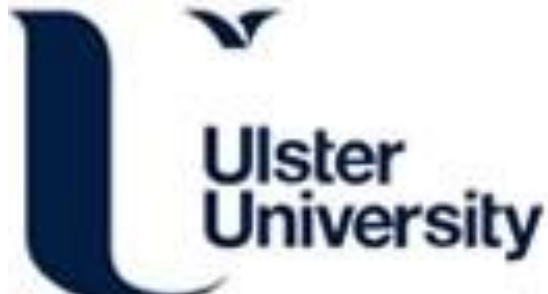

\section{Experimental study of transitional behavior of fully developed under-ventilated compartment fire and associated facade flame height evolution}

Ren, F., Hu, L., Zhang, X., Sun, X., Zhang, J., \& Delichatsios, M. (2019). Experimental study of transitional behavior of fully developed under-ventilated compartment fire and associated facade flame height evolution. Combustion and Flame, 208, 235-245. https://doi.org/10.1016/j.combustflame.2019.07.003

Link to publication record in Ulster University Research Portal

\author{
Published in: \\ Combustion and Flame
}

Publication Status:

Published (in print/issue): 31/10/2019

DOI:

10.1016/j.combustflame.2019.07.003

\section{Document Version}

Author Accepted version

\section{General rights}

Copyright for the publications made accessible via Ulster University's Research Portal is retained by the author(s) and / or other copyright owners and it is a condition of accessing these publications that users recognise and abide by the legal requirements associated with these rights.

\section{Take down policy}

The Research Portal is Ulster University's institutional repository that provides access to Ulster's research outputs. Every effort has been made to ensure that content in the Research Portal does not infringe any person's rights, or applicable UK laws. If you discover content in the Research Portal that you believe breaches copyright or violates any law, please contact pure-support@ulster.ac.uk. 


\section{Combustion and Flame}

\section{Experimental study of transitional behavior of fully developed under-ventilated compartment fire and associated facade flame height evolution

\author{
--Manuscript Draft--
}

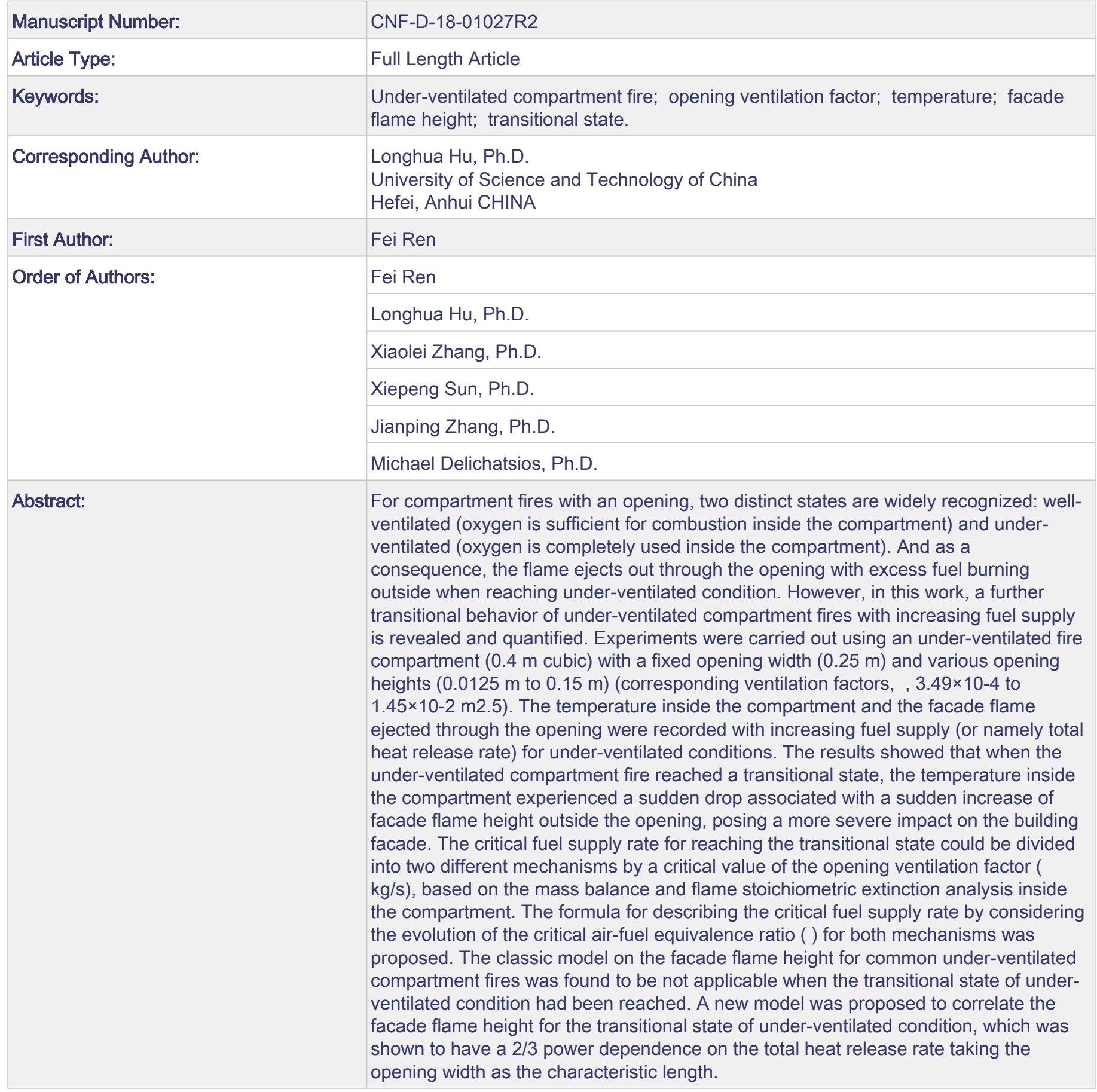




\title{
Experimental study of transitional behavior of fully developed under-ventilated compartment fire and associated facade flame height evolution
}

\author{
Fei Ren ${ }^{\mathrm{a}}$, Longhua $\mathrm{Hu}^{\mathrm{a}^{*}}$, Xiaolei Zhang ${ }^{\mathrm{a}}$, Xiepeng Sun ${ }^{\mathrm{a}}$, \\ Jianping Zhang ${ }^{\mathrm{c}}$, Michael Delichatsios ${ }^{\mathrm{a}, \mathrm{b}}$
}

\author{
a: State Key Laboratory of Fire Science, \\ University of Science and Technology of China, \\ Hefei, Anhui, 230026, China \\ b: Department of Mechanical and Industrial Engineering, \\ Northeastern University, Boston, USA \\ c: FireSERT, School of Built Environment, \\ Ulster University, Newtownabbey BT37 0QB, \\ Northern Ireland, UK
}

\begin{abstract}
*Corresponding author: Tel: (86) 551 63606446; Fax: (86) 55163601669 ; Email address: hlh@ustc.edu.cn; Postal address: State Key Laboratory of Fire Science, University of Science and Technology of China, Hefei, Anhui, 230026, China
\end{abstract}




\section{Abstract}

For compartment fires with an opening, two distinct states are widely recognized: well-ventilated (oxygen is sufficient for combustion inside the compartment) and under-ventilated (oxygen is completely used inside the compartment). And as a consequence, the flame ejects out through the opening with excess fuel burning outside when reaching under-ventilated condition. However, in this work, a further transitional behavior of under-ventilated compartment fires with increasing fuel supply is revealed and quantified. Experiments were carried out using an under-ventilated fire compartment $(0.4 \mathrm{~m}$ cubic $)$ with a fixed opening width $(0.25 \mathrm{~m})$ and various opening heights $(0.0125 \mathrm{~m}$ to $0.15 \mathrm{~m})$ (corresponding ventilation factors, $A \sqrt{H}, 3.49 \times 10^{-4}$ to 1.45 $\left.\times 10^{-2} \mathrm{~m}^{2.5}\right)$. The temperature inside the compartment and the facade flame ejected through the opening were recorded with increasing fuel supply (or namely total heat release rate) for under-ventilated conditions. The results showed that when the under-ventilated compartment fire reached a transitional state, the temperature inside the compartment experienced a sudden drop associated with a sudden increase of facade flame height outside the opening, posing a more severe impact on the building facade. The critical fuel supply rate for reaching the transitional state could be divided into two different mechanisms by a critical value of the opening ventilation factor $([0.5 A \sqrt{H}]=0.0033 \mathrm{~kg} / \mathrm{s})$, based on the mass balance and flame stoichiometric extinction analysis inside the compartment. The formula for describing the critical fuel supply rate by considering the evolution of the critical air-fuel equivalence ratio $(\chi)$ for both mechanisms was proposed. The classic model on the facade flame height for common under-ventilated compartment fires was found to be not applicable when the transitional state of under-ventilated condition had been reached. A new model was proposed to correlate the facade flame height for the transitional state of under-ventilated condition, which was shown to have a $2 / 3$ power dependence on the total heat 
1 release rate taking the opening width as the characteristic length.

2

4

5

7

8

9

10

11

12

13

14

15

16

17

18

19

20

21

22

23

24

25

26

27

28

29

30

31

32

33

34

35

36

37

38

39

40

41

42

43

44

45

46

47

48

49

50

51

52

53

54

55

56

57

58

59

60

61

62

63

64

65

Key words: under-ventilated compartment fire; opening ventilation factor; temperature; facade flame height; transitional state. 


\section{Nomenclature}
$A$
opening area $\left[\mathrm{m}^{2}\right]$
$A \sqrt{H}$
ventilation factor of compartment opening $\left[\mathrm{m}^{2.5}\right]$
$A_{T}$
total exposed surface area of the compartment $\left[\mathrm{m}^{2}\right]$
$C_{d}$
flow coefficient at the opening [dimensionless]
$C_{p}$
specific capacity of gas $[\mathrm{kJ} / \mathrm{kg} \mathrm{K}]$
$g$
gravitational acceleration $\left[\mathrm{m} / \mathrm{s}^{2}\right]$
$H$
opening height $[\mathrm{m}]$
$h_{c}$
total heat loss coefficient from enclosure $\left[\mathrm{kW} /\left(\mathrm{m}^{2} \mathrm{~K}\right)\right]$
characteristic length scale of assumed rectangular fire source [m]
characteristic length scale of assumed rectangular fire source [m]
air inflow rate through the opening $[\mathrm{kg} / \mathrm{s}]$
critical air inflow rate for the two different transitional mechanism $[\mathrm{kg} / \mathrm{s}]$
$\dot{m}_{a, \max }$
air inflow rate for under-ventilated fire $[\mathrm{kg} / \mathrm{s}]$
$\dot{m}_{f}$
fuel supply rate $[\mathrm{kg} / \mathrm{s}]$
$\dot{m}_{f, c}$
critical fuel supply rate for reaching the transitional state $[\mathrm{kg} / \mathrm{s}]$
$\dot{m}_{g}$
gas outflow rate through the opening $[\mathrm{kg} / \mathrm{s}]$
$N$
number of elements in a sample
$\dot{Q}_{\text {total }}$
total heat release rate $[\mathrm{kW}]$
$\dot{Q}_{\text {total }}^{*}$
non-dimensional total heat release rate [dimensionless]
$\dot{Q}_{\text {inside }}$
heat release rate inside the compartment $[\mathrm{kW}]$
$\dot{Q}_{e x}$
excess heat release rate $[\mathrm{kW}]$ 


\begin{tabular}{|ll|}
\hline$\dot{Q}_{e x}^{*}$ & non-dimensional excess heat release rate [dimensionless] \\
$S$ & stoichiometric ratio of mass flow rate of air to fuel [dimensionless] \\
$T_{\infty}$ & ambient air temperature $[\mathrm{K}]$ \\
$W$ & opening width [m] \\
$X_{i}$ & the $i_{\text {th }}$ variable \\
$\bar{X}$ & the average value of the variable \\
$Z_{f}$ & flame height [m] \\
Greek symbols & \\
$\delta X_{i}$ & an uncertainty in the result \\
$\chi$ & air-fuel equivalence ratio [dimensionless] \\
$\rho_{a}$ & ambient air density $\left[\mathrm{kg} / \mathrm{m}^{3}\right]$ \\
$\rho_{g}$ & density of hot gas $\left[\mathrm{kg} / \mathrm{m}^{3}\right]$ \\
$\sigma$ & standard deviation of a population \\
\hline
\end{tabular}




\section{Introduction}

Fire development inside a compartment with an opening (such as a window) is a fundamental scientific problem for fire dynamics. It is widely recognized as basic classic knowledge [1-5] that with an increase in the fuel supply rate or heat release rate, the compartment fire evolves from well-ventilated condition to under-ventilated condition. For a fully developed under-ventilated compartment fire, the air inflow rate (commonly taken as $\dot{m}_{a}=0.5 A \sqrt{H} \quad$ [3], where $A \sqrt{H}$ is the ventilation factor, $A$ is the opening area and $H$ is the opening height) is not sufficient to burn all the fuel inside the compartment (maximum heat release rate inside the compartment as $1500 A \sqrt{H} \mathrm{~kW}$ [6-8]). The unburnt excess fuel flows out through the opening producing a facade flame with an excess heat release rate $\left(\dot{Q}_{e x}=\dot{Q}_{\text {total }}-1500 A \sqrt{H} \mathrm{~kW}[6,7,9]\right)$.

Based on the energy balance analysis, Delichatsios [10] proposed a correlation of the temperature evolution inside the compartment for both well-ventilated and under-ventilated conditions. It was found that the temperature increased with increasing of heat release rate for well-ventilated condition; whereas it remained nearly constant for under-ventilated condition, as the heat release rate inside the compartment $(1500 A \sqrt{H} \mathrm{~kW})$ was controlled by the maximum air mass inflow ( $\dot{m}_{a}=0.5 A \sqrt{H}$ ) or the corresponding burning rate for a under-ventilated fire [11-13]. The facade flame height through the opening at under-ventilated condition, as an important parameter to quantify the impact of the external fire upon the facade as well as the fire spread over the facade, had also been widely investigated [14-18]. Lee and Delichatsios [7,14] proposed that the ejected facade flame can be considered as that produced by a rectangular source siting at the neutral plane of the opening, with two physical length scales $\left(\ell_{1}=(A \sqrt{H})^{2 / 5}\right.$ parallel to facade; $\ell_{2}=\left(A H^{2}\right)^{1 / 4}$ perpendicular to facade) representing the exiting buoyant convective flow condition at the opening. 
The facade flame height $\left(Z_{f}\right)$ was shown to be well correlated to the excess heat release rates $\left(\dot{Q}_{e x}=\dot{Q}_{\text {total }}-1500 A \sqrt{H}\right)$ employing the proposed length scale [7]:

$$
\frac{Z_{f}}{\ell_{1}}=f\left(\frac{\dot{Q}_{e x}}{\rho_{a} c_{p} T_{a} \sqrt{g} \ell_{1}^{5 / 2}}\right)=f\left(\frac{\dot{Q}_{\text {total }}-1500 A \sqrt{H}}{\rho_{a} c_{p} T_{a} \sqrt{g} \ell_{1}^{5 / 2}}\right)
$$

One important assumption in the previous studies and analyses is that the air mass flow rate into the compartment is equal to the gas mass flow rate out of the compartment $\left(\dot{m}_{a} \approx \dot{m}_{g}\right)$ [6]. This is based on the fact that the air mass inflow rate is usually far greater than the fuel supply flow rate $\left(\dot{m}_{a} \gg \dot{m}_{f}\right.$ ), although the complete mass balance suggests $\dot{m}_{g}=\dot{m}_{a}+\dot{m}_{f}$. However, this assumption ceases to be not valid if the mass flow rate of the fuel supply is comparable to the air mass inflow rate. This is particularly important when the opening height is small (i.e., small ventilation factor by noting that the air mass inflow rate is proportional to the $3 / 2$ power of the opening height, $\dot{m}_{a} \sim A \sqrt{H} \sim H^{3 / 2}$ ) and as a result a small air mass inflow rate [19-21]. It could be expected that for a fully developed compartment fire (i.e., after flashover), the temperature of the wall and ceiling could be very high that could provide strong radiation feedback heat flux to the fuel surface. So that the flow rate of pyrolysis gases (fuel) should be still very high, although the oxygen inside the compartment might be not enough to sustain the flaming combustion with an under-ventilated condition. It was found that the fuel mass flux could reach the value of 30 70 $\mathrm{g} /\left(\mathrm{m}^{2} \mathrm{~s}\right)$ for a fully developed fire [22]. In contrast, considering a common window size of $1 \mathrm{~m} \times 1 \mathrm{~m}$ for a real room, the maximum air mass inflow rate could be about $500 \mathrm{~g} / \mathrm{s}\left(0.5 \mathrm{AH}^{1 / 2}\right)$. If taking averaged fuel mass flux of $50 \mathrm{~g} /\left(\mathrm{m}^{2} \mathrm{~s}\right)$, this means that a fuel surface area of only 3 to $5 \mathrm{~m}^{2}$ or higher (which is common for a room), the fuel mass flow rate could be comparable to the air mass flow rate, i.e., with a mass flow rate ratio of $0.3 \sim 0.5$ or higher. So, there should be a transitional state when the 
fuel supply $\left(\dot{m}_{f}\right)$ inside the compartment increases to a relatively high considerable level, for which the classic knowledge and correlation on under-ventilated compartment fire as well as the facade flame height through the opening might not be reliable. This remains a knowledge margin for understanding of compartment fire.

The importance of this transitional state as an essential phenomenon for a fully developed under-ventilated compartment fire was mentioned in an early study by Thomas [23]. It was commented [23] that this transitional state could be of more practical interest as it could be anticipated that air entry through the opening would be prohibited eventually if the fuel gas flow became large enough that all the flames would be outside the opening. The transitional state as expected by Thomas (all the fuel burn outside with no flame inside the room) showed to occur in a real fire accident [24]. Moreover, it can be also expected that this phenomenon could be much easier to happen if a liquid or gas leakage fire occurred inside a compartment.

Nevertheless, there is still no experimental work in the literature to quantify this basic under-ventilated compartment fire transition scenario, and hence how the facade flame behaves outside the opening and what the scaling law of the flame height is, when the transitional state of fully developed under-ventilated compartment fire is reached.

In the present study, experiments were carried out for under-ventilated compartment fires with increasing fuel supply to reach the transitional state for various opening sizes. The evolutions of temperature inside the compartment and facade flame height outside the opening were quantified. The critical condition for reaching the transitional state of fully developed under-ventilated compartment fire was clarified; and a new model for the facade flame height under this transitional state was also developed. 


\section{Experiments}

A reduced-scale experimental model (based on Froude similarity $[25,26]$ ) consisting of a cubic compartment (dimensions: $0.4 \mathrm{~m})$ and a facade of $1.6 \mathrm{~m}(H) \times 1.2 \mathrm{~m}(W)$ was employed, as shown in Fig.1. The compartment was made up with a $1 \mathrm{~mm}$ thick steel plate and the $0.03 \mathrm{~m}$ thick ceramic fiber boards were attached to the compartment inner surface for thermal insulation (thermal properties: density, thermal conductivity and specific heat is $285 \mathrm{~kg} / \mathrm{m}^{3}, 0.18 \mathrm{~W} /(\mathrm{m} \cdot \mathrm{K})$ and 1390 $\mathrm{J} /(\mathrm{kg} \cdot \mathrm{K})$, respectively; thermal inertia calculated to be about $267 \mathrm{~J} /\left(\mathrm{m}^{2} \cdot \mathrm{K} \cdot \mathrm{S}^{0.5}\right)$. The characteristic time for reaching steady state with our experimental setup can be calculated to be $t=\frac{\delta^{2}}{4[k /(\rho c)]}=\frac{\left(3 \times 10^{-2} \mathrm{~m}\right)^{2}}{4 \times\left[0.18 \mathrm{~W} /(\mathrm{mK}) /\left(285 \mathrm{~kg} / \mathrm{m}^{3} \times 1390 \mathrm{~J} /(\mathrm{kgK})\right)\right]}=495 \mathrm{~s}$. The experiments are confirmed to reach steady state, as evidenced by the temperature history curve shown in Fig. 1 (a). A $0.2 \mathrm{~m}$ steel-welded square porous propane burner was used as the fire source at the center of the compartment, the burning surface was flush with the floor with small circular holes (diameter: $5 \mathrm{~mm}$ ) drilled on the surface at a spacing of $1 \mathrm{~cm}$. Employing a gas burner, rather than a solid or liquid fuel fire source, will have the fuel supply controllable, which benefits to resolve the aerothermodynamics of the problem. The fuel supply flow rates were controlled by a mass flowmeter (accuracy of 0.01 SLPM (Standard Liter Per Minute)). The dynamic pressure differential $\left(\frac{1}{2} \rho v^{2}:\right.$ in the magnitude of $\left.10^{-6} \sim 10^{-2} \mathrm{~Pa}\right)$ caused by the fuel discharge momentum at the fire source could be negligible comparing to the thermal buoyancy-induced pressure ( $\Delta P=\Delta \rho g h$ : in the magnitude of $10^{1} \mathrm{~Pa}$ ). Seven openings were considered, with a fixed width $(0.25 \mathrm{~m})$ and various opening heights from $0.0125 \mathrm{~m}$ to $0.15 \mathrm{~m}$, representing different ventilation factors $(A \sqrt{H})$. 
Table 1 Summary of experimental conditions.

\begin{tabular}{ccccc}
\hline $\begin{array}{c}\text { Opening size } \\
(W \times H, \mathrm{~cm})\end{array}$ & $\begin{array}{c}\text { Ventilation factor } \\
\left(A \sqrt{H}, \mathrm{~m}^{2.5}\right)\end{array}$ & $\begin{array}{c}\text { Calculated critical air } \\
\text { mass flow rate of } \\
\text { under-ventilated } \\
\dot{m}_{a}=0.5 A \sqrt{H}{ }^{[1,3]}(\mathrm{kg} / \mathrm{s})\end{array}$ & $\begin{array}{c}\text { Fuel supply flow rate } \\
\text { range } \dot{m}_{f}(\mathrm{~kg} / \mathrm{s})\end{array}$ & $\begin{array}{c}\text { Fuel supply } \\
\text { HRR range } \\
(\mathrm{kW})\end{array}$ \\
\hline $25 \times 1.25$ & $3.49 \times 10^{-4}$ & $1.75 \times 10^{-4}$ & $(0.153-2.14) \times 10^{-4}$ & $0.77-10.76$ \\
$25 \times 2.5$ & $9.88 \times 10^{-4}$ & $4.94 \times 10^{-4}$ & $(0.153-2.75) \times 10^{-4}$ & $0.77-13.84$ \\
$25 \times 5$ & $2.80 \times 10^{-3}$ & $1.40 \times 10^{-3}$ & $(0.61-2.75) \times 10^{-4}$ & $3.07-13.84$ \\
$25 \times 7.5$ & $5.14 \times 10^{-3}$ & $2.57 \times 10^{-3}$ & $(0.61-2.75) \times 10^{-4}$ & $3.07-13.84$ \\
$25 \times 10$ & $7.91 \times 10^{-3}$ & $3.95 \times 10^{-3}$ & $(0.61-9.15) \times 10^{-4}$ & $3.07-46.12$ \\
$25 \times 12.5$ & $1.10 \times 10^{-2}$ & $5.53 \times 10^{-3}$ & $(0.61-13.4) \times 10^{-4}$ & $3.07-67.63$ \\
$25 \times 15$ & $1.45 \times 10^{-2}$ & $7.26 \times 10^{-3}$ & $(0.61-22.9) \times 10^{-4}$ & $3.07-115.28$ \\
\hline
\end{tabular}

A CCD camera (50 fps; sensor size $8.5 \mathrm{~mm}$ with 3,000,000 pixels) was employed to record the ejected flame height. An image processing program was used to get the average flame contours, and to quantify the ejected flame height. As shown in Fig. 1(b), the original flame image was converted to grey-scale image and further to binary image using the Otsu method [27] employing MATLAB program. Flame intermittency distribution was then obtained by averaging the values of these consecutive binary images in each pixel position [28]. Then, the flame intermittency distribution contour was used to represent one experimental case to get the mean flame dimension values at intermittency $=0.5$. Two thermocouple arrays (four $0.5 \mathrm{~mm}$ diameter K-type thermocouples with vertical interval of $0.05 \mathrm{~m})$ were allocated at the inner and outer corners $(0.05 \mathrm{~m}$ to both adjacent walls). The temperature measurements were calibrated with radiation error $[29,30]$ by employing two thermocouples of different diameters $(0.5 \mathrm{~mm}, 1 \mathrm{~mm})$ at the same location. The temperature error due to the radiation loss was found to be less than $9 \%$. For each case, the fuel supply heat release rate was maintained at a given level for 15 minutes to reach a steady state, which was evidenced by the fact that the time variation temperature curve (exemplified in Fig. 1) reached the steady state. All the experimental conditions are listed in Table 1 for different opening dimensions 
(ventilation factor range from $3.49 \times 10^{-4}$ to $1.45 \times 10^{-2}$ ) and fuel supply heat release rates (a wide range to ensure that compartment fire developed from well-ventilated to transitional state). In total, 103 test conditions were examined. Each test condition was repeated 3 times, and the averaged values were used for discussions and analysis. Tables 2 and 3 show the estimated uncertainties of the measured temperature and facade flame height for the opening size of $25 \mathrm{~cm}(W) \times 5 \mathrm{~cm}(H)$ as an example by using the method provided by Morffat [31], in which the experimental uncertainty can be estimated with $X_{i}=X_{i}($ measured $) \pm \delta X_{i}, \quad \sigma=\sqrt{\sum_{i=1}^{N}\left(X_{i}-\bar{X}\right)^{2} /(N-1)}$, where the value of the $X_{i}($ measured $)$ is the observation in a single-sample experiment, the value of $\delta X_{i}$ represents $2 \sigma$ for a single-sample analysis, $N$ is the times of the repeated experiments, $\sigma$ is the standard deviation of the population of possible measurements. The relative uncertainty ( $2 \sigma /$ Average $)$ for temperature and flame height for all the test conditions is found to be less than $7 \%$ with $95 \%$ confidence.

Table 2 Measurement uncertainty estimation for temperature inside the compartment.

\begin{tabular}{|c|c|c|c|c|c|c|c|c|}
\hline \multirow{2}{*}{$\begin{array}{l}\text { Test } \\
\text { No. }\end{array}$} & \multirow{2}{*}{$\begin{array}{l}\text { HRR } \\
(\mathrm{kW})\end{array}$} & \multirow{2}{*}{$\begin{array}{c}\text { Fire } \\
\text { condition }\end{array}$} & \multicolumn{3}{|c|}{ Temperature $\left({ }^{\circ} \mathrm{C}\right)$} & \multirow{2}{*}{ Average $\left({ }^{\circ} \mathrm{C}\right)$} & \multirow{2}{*}{$2 \sigma\left({ }^{\circ} \mathrm{C}\right)$} & \multirow{2}{*}{$\frac{2 \sigma}{\text { Average }} \%$} \\
\hline & & & Repeat I & Repeat II & Repeat III & & & \\
\hline 1 & 3.07 & \multirow{3}{*}{$\begin{array}{c}\text { Well- } \\
\text { ventilated }\end{array}$} & 318 & 335 & 320 & 324 & 18.8 & 5.79 \\
\hline 2 & 4.61 & & 388 & 398 & 411 & 399 & 22.8 & 5.72 \\
\hline 3 & 6.92 & & 484. & 501 & 478 & 488 & 24.3 & 4.99 \\
\hline 4 & 7.67 & \multirow{4}{*}{$\begin{array}{c}\text { Transitional } \\
\text { state }\end{array}$} & 312 & 294 & 307 & 304 & 9.18 & 6.03 \\
\hline 5 & 9.22 & & 264 & 254 & 268 & 262 & 18.4 & 5.61 \\
\hline 6 & 12.30 & & 194 & 196 & 206 & 198 & 13.6 & 6.85 \\
\hline 7 & 13.84 & & 198 & 193 & 203 & 198 & 9.61 & 4.85 \\
\hline
\end{tabular}

Table 3 Measurement uncertainty estimation for facade flame height.

\begin{tabular}{|c|c|c|c|c|c|c|c|c|}
\hline \multirow{2}{*}{$\begin{array}{l}\text { Test } \\
\text { No. }\end{array}$} & \multirow{2}{*}{$\begin{array}{l}\text { HRR } \\
(\mathrm{kW})\end{array}$} & \multirow{2}{*}{$\begin{array}{c}\text { Fire } \\
\text { condition }\end{array}$} & \multicolumn{3}{|c|}{ Flame height (m) } & \multirow{2}{*}{ Average (m) } & \multirow{2}{*}{$2 \sigma(\mathrm{m})$} & \multirow{2}{*}{$\frac{2 \sigma}{\text { Average }} \%$} \\
\hline & & & Repeat I & Repeat II & Repeat III & & & \\
\hline 1 & 7.67 & Transitional & 0.465 & 0.486 & 0.474 & 0.475 & 0.020 & 4.29 \\
\hline
\end{tabular}




\begin{tabular}{|c|c|c|c|c|c|c|c|c|c|}
\hline & 2 & 9.22 & state & 0.469 & 0.491 & 0.482 & 0.481 & 0.023 & 4.78 \\
\hline $\begin{array}{l}1 \\
2\end{array}$ & 3 & 12.30 & & 0.506 & 0.534 & 0.529 & 0.523 & 0.030 & 5.81 \\
\hline 3 & 4 & 13.84 & & 0.541 & 0.567 & 0.558 & 0.555 & 0.026 & 4.76 \\
\hline
\end{tabular}

\section{Results and discussion}

\subsection{Temperature evolution inside compartment and flame phenomenon}

Figure 2 presents the measured average temperature inside the compartment with increasing HRR and associated flame characteristics for each opening size. These temperature measurements show to be nearly uniform with a relative difference less than $20{ }^{\circ} \mathrm{C}$ for the under-ventilated condition. Three different types of temperature variation curves can be identified for various openings (ventilation factors):

(1) For the larger openings $(0.25 \mathrm{~m} \times 0.15 \mathrm{~m} ; 0.25 \mathrm{~m} \times 0.125 \mathrm{~m} ; 0.25 \mathrm{~m} \times 0.10 \mathrm{~m})$, the temperature inside the compartment first increases (stage I, flame within the compartment) and then slightly decreases (stage II, flame stays at the upper part of the opening) with fire growth changing from well-ventilated to under-ventilated conditions, which is well recognized in previous experiments and theory $[7,10]$. However, when the heat release rate is further increased, a transitional behavior (stage III, a transitional state of under-ventilated condition) is found manifested by the fact that the temperature inside the compartment experiences a sudden drop to a relatively low level (indicating no combustion inside the compartment and all the fuels burn outside). This state is also accompanied by an ejected flame that fills the whole opening and a considerable increase of flame height of the ejected flame.

(2) For the medium openings $(0.25 \mathrm{~m} \times 0.075 \mathrm{~m} ; 0.25 \mathrm{~m} \times 0.05 \mathrm{~m} ; 0.25 \mathrm{~m} \times 0.025 \mathrm{~m})$, the temperature inside the compartment first increases (stage I, flame within the compartment) and then suddenly decreases to a relatively low level with the flame filling the whole opening at the moment 
of flame ejecting outside (stage III, transitional state). The classic ventilation-controlled condition is not observed for these cases.

(3) Finally, for the smallest opening $(0.25 \mathrm{~m} \times 0.0125 \mathrm{~m})$, the highest gas temperature inside the compartment is observed for the case with the lowest HRR. The temperatures at different locations are nearly the same indicating the gases inside the compartment are completely well-mixed. With increasing HRR, temperature continues to decrease. The fact that the maximum temperature observed is less than $200{ }^{\circ} \mathrm{C}$ indicates that the gaseous fuel cannot burn inside the compartment and the ejected flame fills the whole opening (stage III, similar to the transitional state observed for above openings).

It can be seen from above observations that there is a basic transitional behavior when the fuel supply heat release rate reaches a critical value (indicated by red circles in Fig.2). After that, no air flows into the compartment resulting in fire extinction inside the compartment and a sudden increase of the flame height on the facade. This state is in accordance with the state that was expected in the early study by Thomas [23], although it was beyond the range of those early experiments. Thomas investigated the effect of fuel surface area on the gross rate of fuel decomposition and heat release inside the compartment and found that the heat transfer first increased and then showed a rapid falling off with the increasing of the gross rate of gaseous fuel flow. And the maximum heat transfer decreased with the decreasing of window area, which was consistent with the temperature evolution shown in Fig.2 for different opening area.

\subsection{Theoretical analysis and model on critical fuel mass flow rate of transition state}

The transition behavior mentioned above can be explained by the theoretical analysis based on mass conservation and flame extinction inside the compartment. When considering the fuel supply 
mass flow rate inside the compartment, the conservation of mass therefore demands that the gases exiting the enclosure must equal the air entering the enclosure plus the mass produced in the enclosure, expressed as

$$
\dot{m}_{a}+\dot{m}_{f}=\dot{m}_{g}
$$

It has been established [6] that the air mass inflow rate through the opening can be expressed as according to the analysis of the mass balance based on the neutral plane at the opening,

$$
\dot{m}_{a}=\frac{\frac{2}{3} C_{d} \sqrt{2 \rho_{a}\left(\rho_{a}-\rho_{g}\right) g} A \sqrt{H}}{\left(\left(\frac{1+\dot{m}_{f} / \dot{m}_{a}}{\sqrt{\rho_{g} / \rho_{a}}}\right)^{2 / 3}+1\right)^{3 / 2}}
$$

It is also found [6] that the values of density term $1 /\left(\sqrt{\rho_{g} / \rho_{a}}\right)^{2 / 3}$ and $\sqrt{\rho_{a}\left(\rho_{a}-\rho_{g}\right)}$ in Eq. (3) varies from 1.44 to 1.71 and from 0.97 to 1.07 when the temperature range from $600^{\circ} \mathrm{C}$ to $1200^{\circ} \mathrm{C}$. Taking an average value of 1.6 for $1 /\left(\sqrt{\rho_{g} / \rho_{a}}\right)^{2 / 3}$ and 1.0 for $\sqrt{\rho_{a}\left(\rho_{a}-\rho_{g}\right)}$, Eq. (3) can be further simplified as

$$
\dot{m}_{a}=\frac{2.1 A \sqrt{H}}{\left(1.6\left(1+\dot{m}_{f} / \dot{m}_{a}\right)^{2 / 3}+1\right)^{3 / 2}}
$$

The above formula shows that the air mass inflow decreases with increasing of fuel supply. This is also indicated by simplified analysis done by Delichatsios [32] with an equation developed for air mass inflow rate in relation to the fuel mass flow rate, taking $T_{a} / T_{g} \approx 0.25\left(T_{a}\right.$ is the air temperature and $T_{g}$ is the gas temperature), which is expressed as,

$$
\dot{m}_{a}=0.5 A \sqrt{H}-0.53 \dot{m}_{f}
$$

As shown in Fig.3, the variation of air mass inflow with fuel mass flow rate based on Eqs. (4) and (5) agree well. They both show that: (1) When the fuel mass flow rate is negligible (i.e., $\dot{m}_{f} \approx 0$ ), 
Eqs. (4) and (5) can be written as $\dot{m}_{a, \max } \approx 0.5 A \sqrt{H}$, which represents the air mass inflow rate for an under-ventilated fire as well reported previously [3, 6]; and (2) with the increasing fuel mass flow rate, the air mass inflow rate would decrease and finally becomes zero (i.e., $\dot{m}_{a}=0$ ) when the fuel mass flow rate is sufficiently large. It can be anticipated that when the air mass inflow rate is sufficiently low (or corresponding to a sufficiently large fuel supply mass flow rate), the oxygen concentration inside the compartment will be not enough to sustain the flame, which will lead to flame extinction. So, there will be a transition behavior (stage III, as shown in Fig.2) when the fuel mass flow rate reaches the critical value $\left(\dot{m}_{f, c}\right)$, which should depend on the opening size (i.e., ventilation factor).

Several previous reports claimed the flame extinction behavior inside a compartment with complex flow (mixing) behavior as the consequence of oxygen lean inside the compartment $[33,34]$. Here in the present study, the parameter $\chi\left(\frac{\dot{m}_{a} / \dot{m}_{f}}{S}=\frac{\dot{m}_{a} / \dot{m}_{f}}{\left(\dot{m}_{a} / \dot{m}_{f}\right)_{\text {stoich }}}\right)$ representing the air-fuel equivalence ratio inside the compartment is introduced to determine the oxygen lean condition leading to the flame extinction. The transition behavior (flame extinction) will occur if the air-fuel equivalence ratio $(\chi<1)$ reaches a critical value,

$$
\dot{m}_{a}=\chi S \dot{m}_{f}
$$

where $S$ is the stoichiometric ratio of air mass inflow rate to the fuel mass flow rate ( $S=16$ for propane used in our work). Substituting Eq. (6) into Eq. (5), the model regarding the critical fuel mass flow rate for the transitional state can be expressed as:

$$
\dot{m}_{f, c}=\frac{0.5 A \sqrt{H}}{\chi S+0.53}
$$

From the experimental results (as shown in Fig.2), two transitional mechanisms can be identified for 
the different ventilation factor. For the relatively small openings $(0.25 \mathrm{~m} \times 0.075 \mathrm{~m}, 0.25 \mathrm{~m} \times 0.05 \mathrm{~m}$, $0.25 \mathrm{~m} \times 0.025 \mathrm{~m}, 0.25 \mathrm{~m} \times 0.0125 \mathrm{~m})$, the compartment fire developed from the well-ventilated condition to the transitional state directly (two-stage transition). However, for the relatively large openings $(0.25 \mathrm{~m} \times 0.15 \mathrm{~m}, 0.25 \mathrm{~m} \times 0.125 \mathrm{~m}, 0.25 \mathrm{~m} \times 0.1 \mathrm{~m})$, the compartment fire first developed to the under-ventilated condition, then to the transitional state (three-stage transition). Therefore, it indicates that the value of $\chi$ shows different behaviors for relatively small- (two-stage transition) and relatively large openings (three-stage transition). There are two questions to be solved for the value of $\chi$ in Eq. (7): (1) what is the critical opening size, or ventilation factor, for dividing above two kinds of transitions; and (2) how does the values of $\chi$ depend on the ventilation factor of the opening for each mechanism.

Figure 4 plots the air mass inflow rate calculated using Eq. (5) against with the fuel supply flow rate for the three relatively large openings $(0.25 \mathrm{~m} \times 0.15 \mathrm{~m}, 0.25 \mathrm{~m} \times 0.125 \mathrm{~m}, 0.25 \mathrm{~m} \times 0.10 \mathrm{~m})$, as the temperature for under-ventilated compartment fire (stage II) of these three opening sizes is within the scope of Eq. (5) showing well-mixed condition. A linear relation is obtained between the critical fuel mass flow rate and the air inflow rate (minimum air/fuel mass flow rate for reaching the transitional state):

$$
\dot{m}_{a, c}=1.315 \dot{m}_{f, c}+0.0033
$$

Then, an intercept of Eq. (8) with the vertical axis (Y-axis) could be found, which corresponds to the critical air mass inflow rate or opening ventilation factor $\left([0.5 A \sqrt{H}]_{\text {critical }}=0.0033 \mathrm{~kg} / \mathrm{s}\right)$ to have the three-stage transition behavior (Figs. 2a, 2b and 2c). The dividing of these two transitional behaviors based on the critical ventilation factor $\left([0.5 A \sqrt{H}]_{\text {critical }}=0.0033 \mathrm{~kg} / \mathrm{s}\right)$ for various opening sizes is consistent with the experimental observations in Fig. 2. 
For relatively small openings $([0.5 A \sqrt{H}]<0.0033 \mathrm{~kg} / \mathrm{s})$, the compartment fire develops directly from well-ventilated condition (stage I) to the transitional under-ventilated state (stage III), where the temperature values are not within the scope of application of Eq. (5). Here, it could reasonably assume that their critical fuel mass flow rate for the transitional behavior should just be proportional to the maximum air mass flow rate $\left(\dot{m}_{a, \max }=0.5 A \sqrt{H} \mathrm{~kg} / \mathrm{s}\right)$ that one opening can provide for under-ventilated condition. So, the value of the proportion $\frac{1}{\chi S+0.53}$ in the proposed model Eq. (7) for the transitional state should be a constant. This is shown to be well verified by the experimental data (as the sub-figure shown in Fig. 4). The experimental results of the critical fuel supply mass flow rates for these relatively small opening could be well correlated by Eq. (7), assuming a constant value of $\chi(=0.74)$. This also indicates that the air-fuel equivalence ratio $(\chi)$ of critical air mass inflow rate to a given fuel flow rate to reach the critical transitional state is independent of opening size (or ventilation factor) for the two-stage transition.

For the relatively large openings $([0.5 A \sqrt{H}]>0.0033 \mathrm{~kg} / \mathrm{s})$, the compartment fire develops from well-ventilated condition (stage I) to the under-ventilated condition (stage II) and then to the transitional state (stage III). It is noted that a significant difference between the three-stage transition for the relatively large openings and the two-stage transition for relatively small opening is the maximum temperature inside the compartment (Fig. 2). It is much higher for the three-stage transition (over $800^{\circ} \mathrm{C}$ ) than that of the two-stage transition. The temperature inside the compartment will significantly affect the flame extinction, that is, flame is harder to reach extinction if the temperature is higher. So, the temperature effect, which is determined by the ventilation and opening factor, should be further accounted for the three-stage transition relative to two-stage transition. The value of $\chi$ can be calculated by using the theoretical model (Eq. (4)) for the relatively large 
openings. It was found that the value of $\chi$ decreased with the increasing of the ventilation factor. Considering the higher temperature inside the compartment of the under-ventilated period for the relatively larger opening as discussed above, it could be anticipated that the value of $\chi$ should be influenced by the temperature and reasonably be a function of the opening factor $\left(A \sqrt{H} / A_{T}\right)$ or its dimensionless form, $\rho_{a} c_{P} A \sqrt{g H} / h_{c} A_{T}$. Figure 5 presents the value of $\chi$ obtained in the experiments for the relatively large openings showing three-stage transition as a function of the dimensionless form of opening factor, $\rho_{a} c_{P} A \sqrt{g H} / h_{c} A_{T}$. A correlation of the value of $\chi$ can be developed as:

$$
\chi=1.69\left(\rho_{a} c_{P} A \sqrt{g H} / h_{c} A_{T}\right)^{-1.78}
$$

The intersection point of the above correlation with the line of constant value of $\chi(=0.74)$ is reached at the abscissa of 1.59 . Thus, the value of the critical ventilation factor $(A \sqrt{H})$ can be calculated range from 0.00658 to 0.00663 by taking the total exposed surface area of the compartment $\left(A_{T}\right)$ to be $0.935(0.25 \mathrm{~m} \times 0.10 \mathrm{~m})$ and $0.94125(0.25 \mathrm{~m} \times 0.075 \mathrm{~m})$. This is in good accordance with the observation in Fig. 4 as the critical air mass inflow rate or opening ventilation factor $\left([0.5 A \sqrt{H}]_{\text {critical }}=0.0033 \mathrm{~kg} / \mathrm{s}\right)$ to divide the two-stage transition and the three-stage transition. It could be interesting to see how the critical values of $\chi$ compared to the flammability limit of the fuel. The upper flammability limit of mixture (propane and air) is 9.5\% (volume percentage) and the lower flammability limit of propane is $2.1 \%$ (volume percentage). The air-fuel equivalence ratio can be calculated to be 0.42 and 2.05 for the upper and lower flammability limits, respectively. Figure 5 shows a comparison of the air-fuel equivalence ratio $(\chi)$ obtained in this work (diffusion combustion) with the flammability limit of the mixture (air and propane). It can be seen that the value of upper flammability limit for the two-stage transition should be higher than the mixture due to the vitiation 
effect [35]. The vitiation effect of the large amounts of combustion products and hot gas inside the compartment significantly influence the mixing of fuel and air. So, the upper flammability limit should be higher than 0.42 for compartment fire condition, and the upper flammability limit of compartment fire was found to be 0.74 (volume percentage: 5.7\%) herein for the two-stage transition. For the three-stage transition, the temperature has a significant effect. It is known that [36] the flammability limit should decrease with increase of temperature, which for the current study as a result of the increased opening size, or namely opening factor. This trend is also consistent with the observation for the three-stage transition shown in Fig. 5, where the value of $\chi$ decreases with increasing of opening factor.

Then, a complete piece-wise function could be finally obtained for the value of $\chi$ expressed as:

$$
\chi= \begin{cases}0.74 & 0.5 A \sqrt{H} \leq 0.0033 \\ 1.69\left(\rho_{a} c_{P} A \sqrt{g H} / h_{c} A_{T}\right)^{-1.78} & 0.5 A \sqrt{H}>0.0033\end{cases}
$$

Using Eq. (10) and Eq. (7), a prediction model for the critical fuel supply mass flow rate for the compartment fire to reach the transitional state (stage III) is obtained for any given opening ventilation factor:

$$
m_{f, c}= \begin{cases}\frac{0.5 A \sqrt{H}}{0.74 S+0.53} & 0.5 A \sqrt{H} \leq 0.0033 \\ \frac{0.5 A \sqrt{H}}{1.69\left(\rho_{a} c_{P} A \sqrt{g H} / h_{c} A_{T}\right)^{-1.78} S+0.53} & 0.5 A \sqrt{H}>0.0033\end{cases}
$$

Eq. (11a) can be further written in a non-dimensional form (a more general form $0.133 \rho_{a} A \sqrt{g H}$ to replace the maximum air inflow rate $0.5 A \sqrt{H}$ ): 


$$
\frac{m_{f, c}}{0.133 \rho_{a} A \sqrt{g H}}= \begin{cases}\frac{1}{0.74 S+0.53} & \rho_{a} c_{P} A \sqrt{g H} / h_{c} A_{T} \leq 1.6 \\ \frac{1}{1.69\left(\rho_{a} c_{P} A \sqrt{g H} / h_{c} A_{T}\right)^{-1.78} S+0.53} & \rho_{a} c_{P} A \sqrt{g H} / h_{c} A_{T}>1.6\end{cases}
$$

Figure 6 compares the predictions of the critical fuel supply mass flow rate using the proposed model with the experimental data, which shows good agreement. For better comparing the experimental data and prediction model showing the piece-wise function in Eq. (11a), Fig. 7 presents the critical fuel supply mass flow rate as a function of the maximum air mass inflow rate $\left(\dot{m}_{a, \max }=0.5 A \sqrt{H} \mathrm{~kg} / \mathrm{s}\right)$ for under-ventilated fire, or namely, the ventilation factor of the opening. Here, the averaged values of the term $\rho_{a} c_{P} \sqrt{g} / h_{c} A_{T}$ (in the range of $0.9225 \sim 0.935$ with an averaged value of 0.929 ) was used for the three larger openings $\left([0.5 A \sqrt{H}]_{\text {critical }}>0.0033 \mathrm{~kg} / \mathrm{s}\right)$. Then, the critical fuel supply mass flow rates in both regimes could be expressed as a function of $0.5 A \sqrt{H}$ for a comparison in one graph. Figure 7 shows that the experimental results of the two regimes for relatively small and large openings could be both well approached by the proposed piece-wise function. A note here is the generalization of value, $0.5 A \sqrt{H}$, although it has been widely used $[6,10,37,38]$ and validated more recently by a similar model-scale experiment [39]. This could be an open question to be noted herein. Larger scale fire tests should be valuable future work to validate and extend the application range of these correlations.

\subsection{Facade flame height evolution}

Figure 8 presents typical images of flame height evolution with increasing fuel supply heat release rate for two opening sizes $(0.25 \mathrm{~m} \times 0.0125 \mathrm{~m}$ and $0.25 \mathrm{~m} \times 0.15 \mathrm{~m})$, which represents two types of flame ejection behavior for different ventilation factors (the flame base position shown here in Fig. 8(b) is an average value obtained from $30 \mathrm{~s}$ video (totally 1500 frames)): 
(1) For the smaller opening $0.25 \mathrm{~m} \times 0.0125 \mathrm{~m}$ (similar observations for $0.25 \mathrm{~m} \times 0.025 \mathrm{~m}, 0.25$ $\mathrm{m} \times 0.05 \mathrm{~m}, 0.25 \mathrm{~m} \times 0.075 \mathrm{~m}$ ), once the flame ejects out through the opening, the flame base is located at the bottom edge of the opening and the flame fills the whole opening;

(2) For the larger opening $0.25 \mathrm{~m} \times 0.15 \mathrm{~m}$ (similar observations for $0.25 \mathrm{~m} \times 10 \mathrm{~cm}, 0.25 \mathrm{~m}$ $\times 0.125 \mathrm{~m}$ ), when the HRR is small the flame firstly only fills the upper part of the opening after ejection and the flame base is located at around the middle of the opening, which is similar to previous observations $[7,14]$. However, the flame base descends gradually with increasing fuel supply and finally reaches the bottom edge of the opening at the critical transitional state.

As the flame fills the whole opening, there is no air flowing into the compartment through the opening and thus no flaming combustion inside the compartment (although the volatiles could continue to release from the combustible surface which could be still at high temperature, as the radiation feedback from the compartment walls and hot gases to the combustible surface could be still high to support the volatile release). This is evidenced by the sudden drop of the temperature inside the compartment to a much lower level (Fig. 2) as well as the associated sudden increase of facade flame height observed in Fig. 8 (b).

The sudden change of facade flame height for the transition from under-ventilated condition to the transitional state is more clearly shown in Fig. 9, which presents quantitatively the evolution of facade flame height with the fuel supply heat release rate for various openings. For the relatively small openings (opening height less than or equal to $0.075 \mathrm{~m}$ ), the flame height increases gradually with increasing heat release rate (the transitional state occurs once it becomes under-ventilated). For the relative larger openings (opening height more than or equal to $0.1 \mathrm{~m}$ ), flame height firstly increases gradually (common under-ventilated condition, solid symbol), but it is then followed by a 
sudden jump increase (transition to transitional state of under-ventilated condition, hollow symbol) with increasing fuel supply heat release rate.

Figure 10 presents the normalized facade flame height $\left(Z_{f} / \ell_{1}\right)$ versus the dimensionless excess heat release rate $\left(\dot{Q}_{e x}^{*}=\frac{\dot{Q}_{\text {total }}-1500 A \sqrt{H}}{T_{a} \rho_{a} c_{\mathrm{p}} \sqrt{g} \ell_{1}^{5 / 2}}\right.$ ) according to Eq. (1). It shows that the data in common under-ventilated compartment fires (solid symbol) can be well correlated by the classic model (Eq. 1), which falls into two regimes [7] (sub-figure in Fig. 10: a 2/3 power dependence on heat release rate for relative smaller fires, $\dot{Q}_{e x}^{*}<1.3$; whereas a $2 / 5$ power dependence for relative larger fires, $\left.\dot{Q}_{e x}^{*}>1.3\right)$. However, it is clearly shown that the data for transitional state under-ventilated compartment fires (hollow symbol) cannot be represented by the classic model (Eq.1). In the following section we will develop a non-dimensional model for the data in the transitional state.

Figure 11 presents schematically a physical interpretation and modeling of facade flame height for the transitional state of under-ventilated condition (Fig. 11b) and a comparison with the classic model proposed by Delichatsios [7] for common under-ventilated conditions (Fig. 10a). For common under-ventilated condition compartment fires (Fig. 11a), only part of the fuel burns outside $\left(\dot{Q}_{e x}\right)$ represented by a rectangular source model siting at the upper part of the opening whose physical horizontal length scales are $\ell_{1}$ and $\ell_{2}$. However, when the transitional state of under-ventilated condition has been reached (Fig. 10b), all the fuel burns outside the opening and the whole opening is filled with flame. The facade fire condition in this case is fundamentally different from that in the common under-ventilated condition compartment fires (Fig. 11a), but is more similar to that in a wall fire. 
Coutin et al. [40] showed that the flame height for unconfined wall fires generated by a gaseous burner embedded in the walls was independent of the pyrolysis length (the height of the burner, which was arranged vertically) when the flame height was larger than 1.5 times the pyrolysis length. Figure 12 further correlates the facade flame height at the transitional state of under-ventilated compartment fires for various openings against a newly defined dimensionless total heat release rate, using the opening width as the characteristic length scale. All the experimental data of the transitional state of under-ventilated condition for various openings can be correlated well with a $2 / 3$ power dependence of the dimensionless flame height on the dimensionless heat release rate, typically found for wall fires. This result is also consistent with our previous observations that at this state no air flows into the compartment and all fuels are consumed outside the compartment.

$$
\frac{Z_{f}}{W}=3.55\left(\frac{\dot{Q}_{\text {total }}}{\rho_{a} c_{p} T_{a} \sqrt{g} W^{5 / 2}}\right)^{2 / 3}
$$

It is noted that there is some deviation of the correlation from the data of wall fire [38]. This should be due to the inherent difference between facade fire and wall fire. Actually, the facade flame through the compartment opening has a nature feature of horizontal momentum. The flame ejects through the vertical opening for a certain horizontal distance then turns upward. However, for the wall fire, the flame is just driven upward by its buoyancy. It is the horizontal momentum that drives down the flame from upward spreading, which makes the flame height of a facade fire through the opening to be relatively smaller than that of a wall fire, as shown in Fig. 12.

\section{Conclusions}

The present study reports the quantification of a transitional behavior of under-ventilated compartment fire with increasing fuel supply as well as the associated facade flame height evolution, 
which remains a knowledge margin. Major new findings are:

(1) A transitional behavior of under-ventilated compartment fires is observed experimentally when the fuel supply rate increases beyond a critical value. After this transition, no air flows into the compartment and all combustion occurs outside the compartment with the temperature inside the compartment experiencing a sudden drop to relative low level accompanied with a sudden increase of facade flame height outside the opening (Fig.2 and Fig.8);

(2) The reaching of this transitional state with increasing fuel supply has been shown to have two different transition behaviors depending on the opening size. For relative smaller openings $[0.5 \mathrm{~A} \sqrt{\mathrm{H}}]_{\text {critical }}<0.0033 \mathrm{~kg} / \mathrm{s}$, two-stage transition occurs in comparison with three-stage transition for relative larger openings $[0.5 A \sqrt{H}]_{\text {critical }}>0.0033 \mathrm{~kg} / \mathrm{s}$. The fraction $(\chi)$ of the air inflow rate to the stoichiometric requirements for a given fuel flow rate is found to be independent of opening ventilation for relatively small openings $([0.5 A \sqrt{H}]<0.0033 \mathrm{~kg} / \mathrm{s})$, while it deceases with opening factor for relatively large openings $([0.5 A \sqrt{H}]>0.0033 \mathrm{~kg} / \mathrm{s})$. The critical fuel supply flow rates for reaching this transitional state for the two opening conditions are deduced (Eqs. (7) and (11)).

(3) A new non-dimensional model (Fig.11) is proposed to correlate the facade flame height at the transitional state of under-ventilated compartment fires, which is shown to have a $2 / 3$ power dependence (typically found for wall fires) on the dimensionless total heat release rate using the opening width as the characteristic length (Eq. (12) and Fig. 12).

The new findings about the transitional state especially the "flame jump" behavior leading to a sudden increase of flame height will be essential aspect to be noticed in practical fire safety engineering of facade fires through the window. This is important for the fire hazard evaluation, as well for the safety of fire fighter during the fire rescue and firefighting of such scenario. It could be 
interesting to explore more practical significance of this phenomenon as a future notice.

\section{Acknowledgements}

This work was supported jointly by key project of National Natural Science Foundation of China (NSFC) under Grant No. 51636008, NSFC-STINT joint project (USTC-Lund University), Key Research Program of Frontier Sciences, Chinese Academy of Science (CAS) under Grant No. QYZDB-SSW-JSC029 and Fundamental Research Funds for the Central Universities (No. WK2320000035; WK2320000038.

\section{References}

[1] K. Kawagoe, Fire Behavior in Rooms, Report No. 27, Building Research Institute, Ministry of Construction, Tokyo, 1958.

[2] S. Yokoi, Report 34, Report of the Building Research Institute, 1960.

[3] V. Babrauskas, Estimating room flashover potential, Fire Technol. 16 (2) (1980) 94-103.

[4] B. Bøhm, S. Hadvig, Nonconventional fully developed polyethylene and wood compartment fires. Combust. Flame 44(1-3) (1982) 201-221.

[5] T.Z. Harmathy, Ventilation of fully-developed compartment fires. Combust. Flame 37 (1980) 25-39.

[6] B. Karlsson, J.G. Quintiere, Enclosure fire dynamics. CRC, 2000.

[7] Y.P. Lee, M.A. Delichatsios, G.W.H. Silcock, Heat fluxes and flame heights in facades from fires in enclosures of varying geometry, Proc. Combust. Inst. 31 (2007) 2521-2528.

[8] D. Drysdale, An Introduction to Fire Dynamics, second ed., John Wiley \& Sons Ltd., 1999.

[9] I. Oleszkiewicz, HTD, vol. 123, Collected Papers in Heat Transfer, Book No.H00526, 1989, $163-170$.

[10] M.A. Delichatsios, Y. P. Lee, P. Tofilo, A new correlation for gas temperature inside a burning 
enclosure, Fire Safety J. 44 (8) (2009) 1003-1009.

[11] P.H. Thomas, A.J.M. Heselden, M. Law. Fully-developed Compartment Fires: Two Kinds of Behaviour. Fire Research Technical Paper No 18, HM Stationery Office, London, 1967.

[12] T.Z. Harmathy, A new look at compartment fires, Parts I and II. Fire Technol., 8 (1972) 196-217, 326-351.

[13] A. J. M. Heselden, P.H. Thomas, M. Law, Burning rate of ventilation-controlled fires in compartments. Fire Technol. 6(2) (1970) 123-125.

[14] Y.P. Lee, Heat Fluxes and Flame Heights in External Facade Fires, FireSERT, University of Ulster, 2006.

[15] Y. Hasemi, Experimental wall flame heat transfer correlations for the analysis of upward wall flame spread, Fire Sci. Technol. 4 (1984) 75-90.

[16] L.G. Seigel, The projection of flames from burning buildings, Fire Technol. 5 (1) (1969) 43-51.

[17] K. Himoto, T. Tsuchihashi, Y. Tanaka, T. Tanaka, Modeling thermal behaviors of window flame ejected from a fire compartment, Fire Safety J. 44 (2009) 230-240.

[18] Y. Ohmiya, Y. Hori, K. Safimori, et al. Predictive method for properties of flame ejected from an opening incorporating excess fuel. Fire Safety Sci. 4(2000) 375-386.

[19]O. Sugawa, K. Kawagoe, Y. Oka, et al. Burning behavior in a poorly-ventilated compartment fire-ghosting fire. Fire Sci. Technol. 9(2) (1989) 5-14.

[20] Y. Utiskul, J.G. Quintiere, A.S. Rangwala, et al. Compartment fire phenomena under limited ventilation. Fire Safety J. 40(4) (2005) 367-390.

[21] Z.H. Hu, Y. Utiskul, J.G. Quintiere, et al. A comparison between observed and simulated flame structures in poorly ventilated compartment fires. Fire Safety Sci. 8 (2005) 1193-1204.

[22] J.G. Quintiere, B.J. McCaffrey, K. Den Braven. Experimental and theoretical analysis of 
quasi-steady small-scale enclosure fires. Symposium (International) on Combustion. Elsevier, 17(1) (1979) 1125-1137.

[23] P.H. Thomas, A.J.M. Heselden. Behaviour of fully developed fire in an enclosure. Combust. Flame 6(1962) 133-135.

[24] K. Lambert, Rapid Fire Progress: een overzicht, De brandweerman, editie maart '13, 2013 (in Dutch)

[25]Quintiere J G. Scaling Application in Fire Research. Fire Safety J. 15 (1) (1989) 3-29.

[26]F.Z. Mei, F. Tang, X. Ling, J.S. Yu, Evolution characteristics of fire smoke layer thickness in a mechanical ventilation tunnel with multiple point extraction, Appl. Therm. Eng. 111 (2017) 248-256.

[27] N. Otsu, A threshold selection method from gray-level histograms, IEEE T Syst Man CY-S 9 (1979) 62-66.

[28]L.H. Hu, F. Tang, Q. Wang, Z. Qiu, Burning characteristics of conduction-controlled rectangular hydrocarbon pool fires in a reduced pressure atmosphere at high altitude in Tibet. Fuel 111 (2013) 298-304.

[29]A.V. Singh, M. J. Gollner, A methodology for estimation of local heat fluxes in steady laminar boundary layer diffusion flames, Combust. Flame 162 (5) (2015) 2214-2230.

[30]S. Brohez, C. Delvosalle, G. Marlair, A two-thermocouples probe for radiation corrections of measured temperatures in compartment fires. Fire Safety J. 39(5) (2004) 399-411.

[31] R.J. Moffat, Describing the uncertainties in experimental results, Exp. Therm. Fluid Sci. 1 (1988) 3-17.

[32] M.A. Delichatsios, G.W.H. Silcock, X.J. Liu, M. Delichatsios, Y.P. Lee. Mass pyrolysis rates and excess pyrolysate in fully developed enclosure fires. Fire Safety J. 39(1) (2004) 1-21.

[33] Y. Utiskul, J.G. Quintiere, A.S. Rangwala, et al. Compartment fire phenomena under limited 
ventilation. Fire Safety J. 40(4) (2005) 367-390.

[34] A.S.X. Loo, A. Coppalle, P. Aîné. Flame extinction in a ventilation-controlled compartment. Procedia Engineering 62(2013) 301-308.

[35] S. Vilfayeau, N. Ren, Y. Wang, et al. Numerical simulation of under-ventilated liquid-fueled compartment fires with flame extinction and thermally-driven fuel evaporation. Proc. Combust. Inst. 35(3) (2015) 2563-2571.

[36] S. Kondo, K. Takizawa, A. Takahashi, et al. On the temperature dependence of flammability limits of gases. J. Hazard. Mater. 187(1-3) (2011) 585-590.

[37] V. Babrauskas. A closed-form approximation for post-flashover compartment fire temperatures. Fire Safety J. 4(1) (1981) 63-73.

[38] B.J. McCaffrey, J.G. Quintiere, M.F. Harkleroad. Estimating room temperatures and the likelihood of flashover using fire test data correlations. Fire Technol.17(2) (1981) 98-119.

[39] Asimakopoulou E K, Kolaitis D I, Founti M A. Geometrical characteristics of externally venting flames: Assessment of fire engineering design correlations using medium-scale compartment-façade fire tests. J. Loss Preven. Process Indust. 44(2016) 780-790.

[40] M. Coutin, J.M. Most, M.A. Delichatsios, M.M. Delichatsios, Proceedings of the 6th International Symposium on Fire Safety Science, 2000, 729-740. 


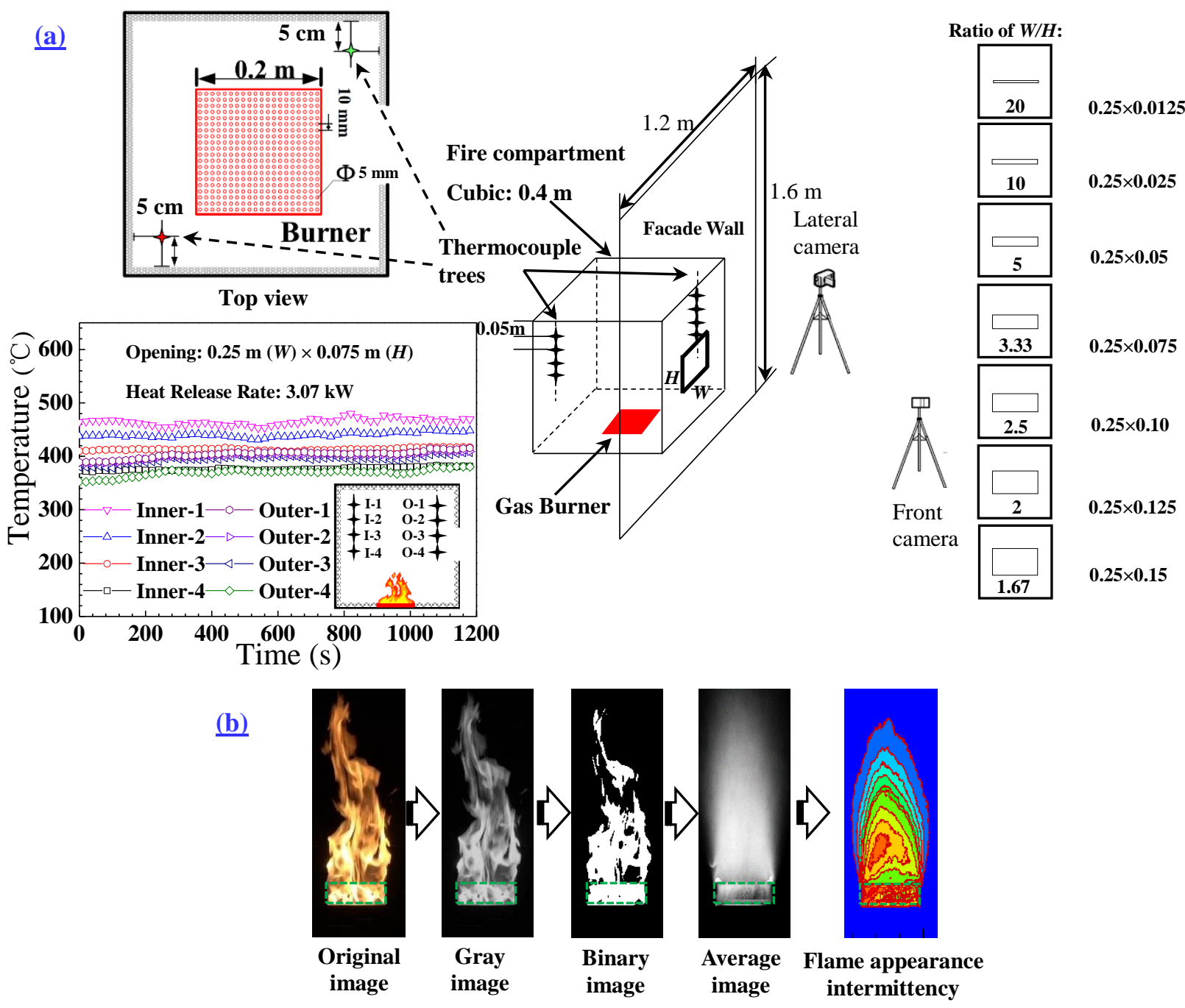

Fig.1 Experimental setup 

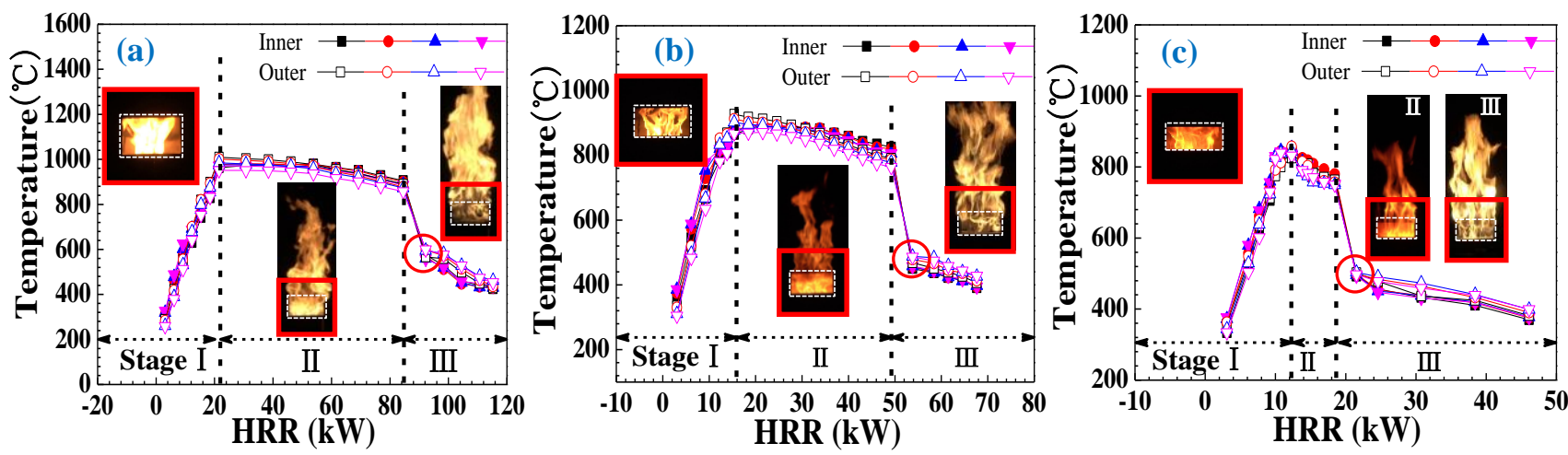

$$
0.25 \mathrm{~m}(W) \times 0.15 \mathrm{~m}(H)
$$

$$
0.25 \mathrm{~m}(W) \times 0.125 \mathrm{~m}(H)
$$

$0.25 \mathrm{~m}(W) \times 0.10 \mathrm{~m}(H)$
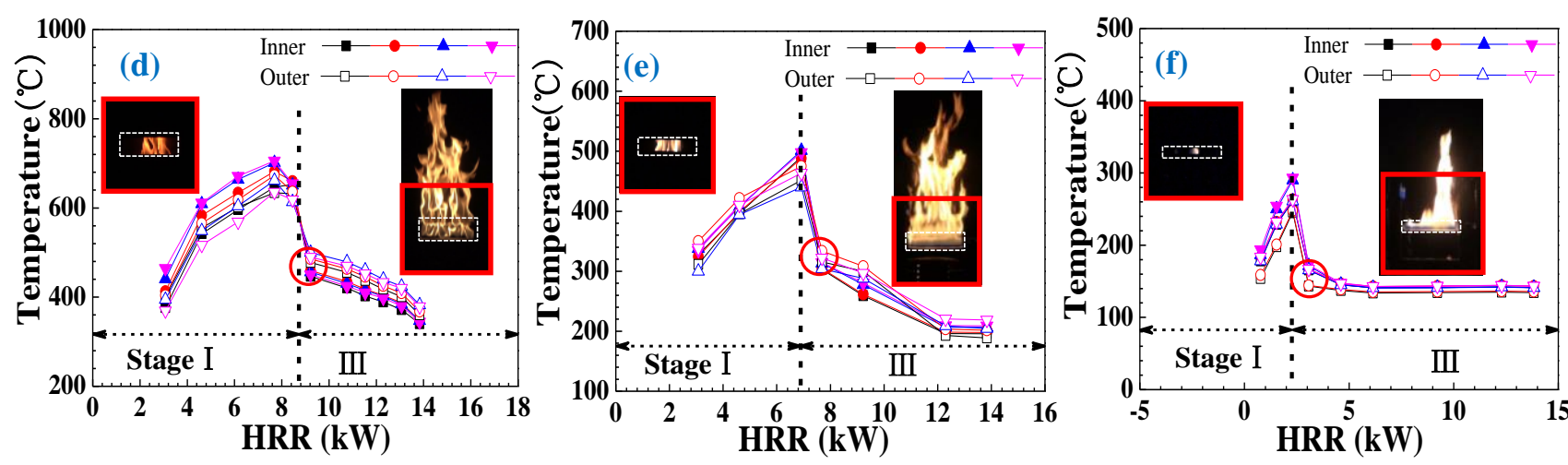

$0.25 \mathrm{~m}(W) \times 0.075 \mathrm{~m}(H)$

$0.25 \mathrm{~m}(W) \times 0.05 \mathrm{~m}(H)$

$0.25 \mathrm{~m}(W) \times 0.025 \mathrm{~m}(H)$

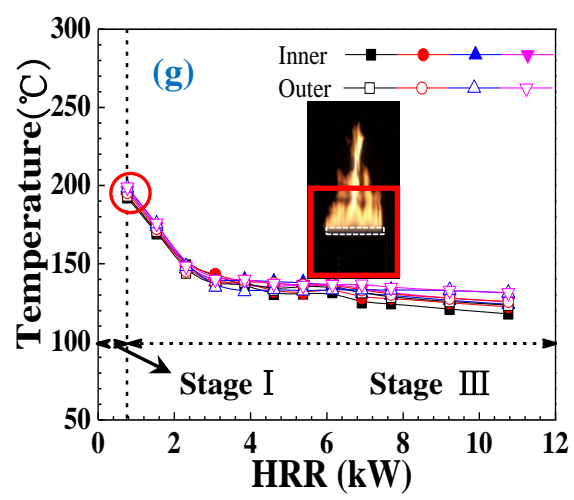

$0.25 \mathrm{~m}(W) \times 0.0125 \mathrm{~m}(H)$

Fig.2 Variation of gas temperature inside the compartment with heat release rate and associated flame phenomenon for each opening (Stage I: well-ventilated state; Stage II: under-ventilated state; Stage III: a transitional state of under-ventilated condition) 


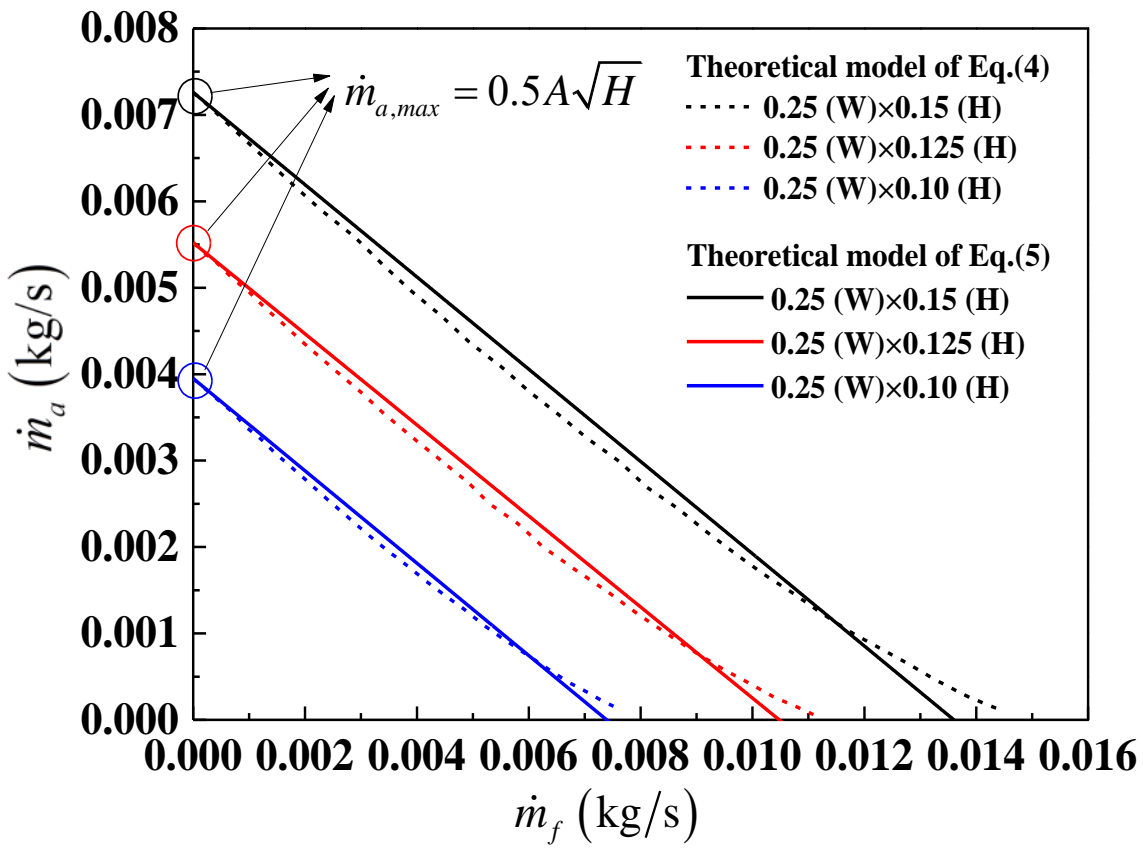

Fig.3 Variation of air mass inflow with fuel mass flow rate based on the theoretical analysis of mass conservation 


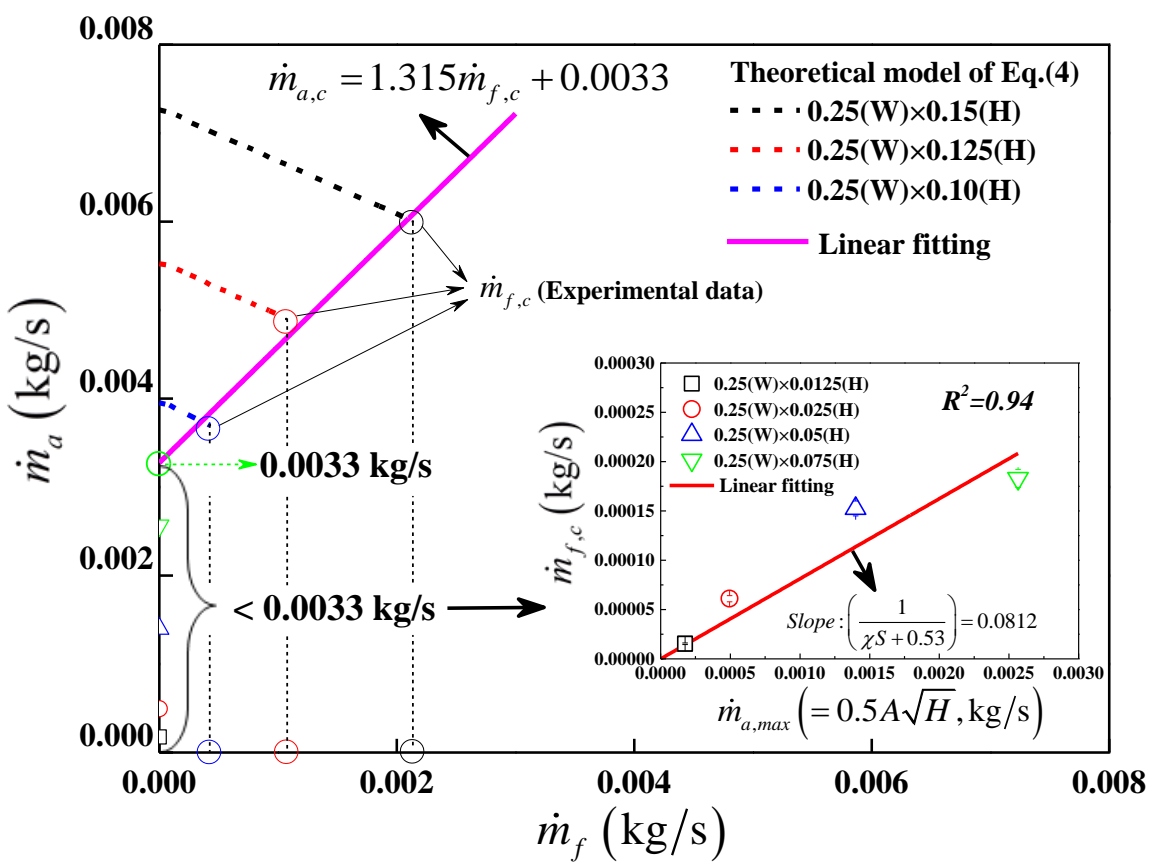

Fig.4 The critical opening size for dividing the two kinds of transitions and the correlation of the critical fuel supply flow rate for relatively small openings reaching the transitional state 
Fig.5 Correlation of the value $\chi$ for critical fuel supply flow rate against the air mass inflow

rate for classical under-ventilated fire

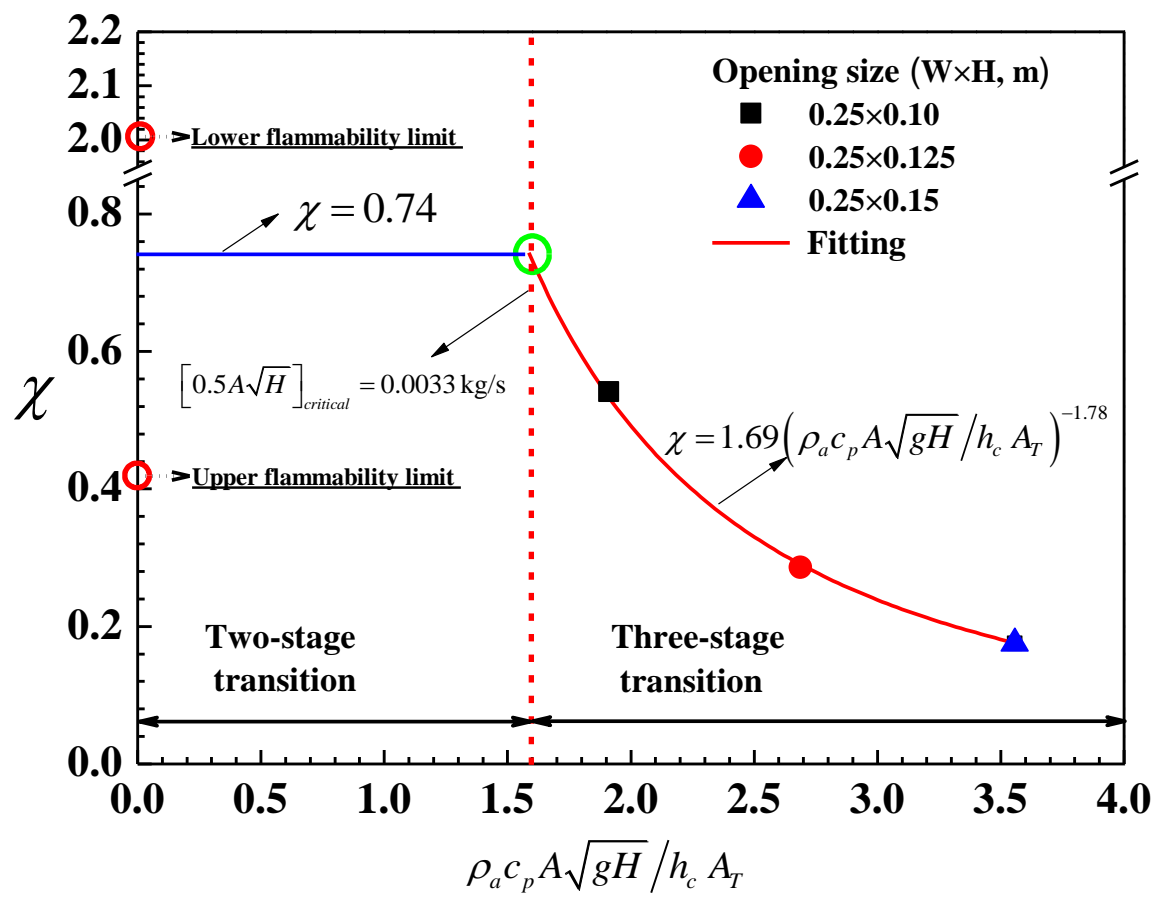




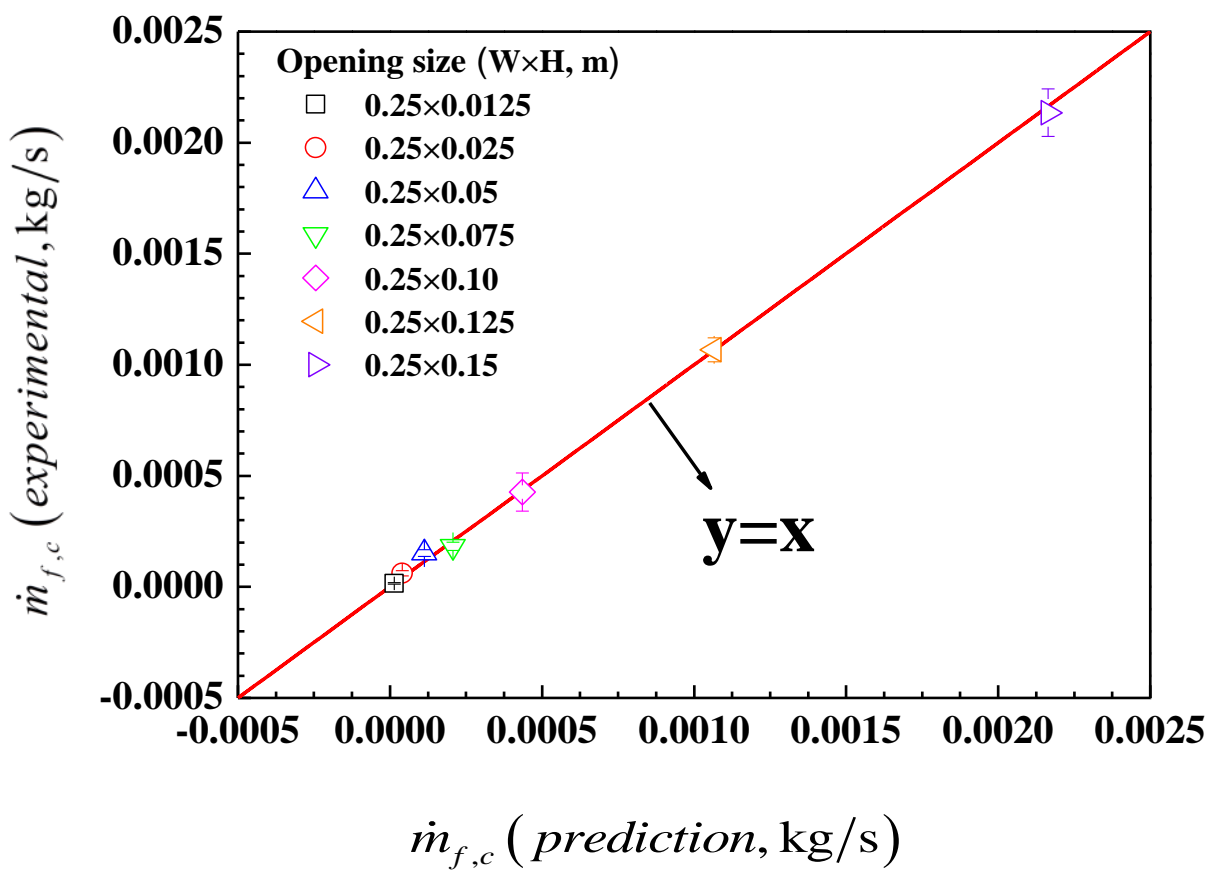

Fig.6 Comparison of experimental values of critical fuel supply mass flow rates with the proposed model for various opening sizes 


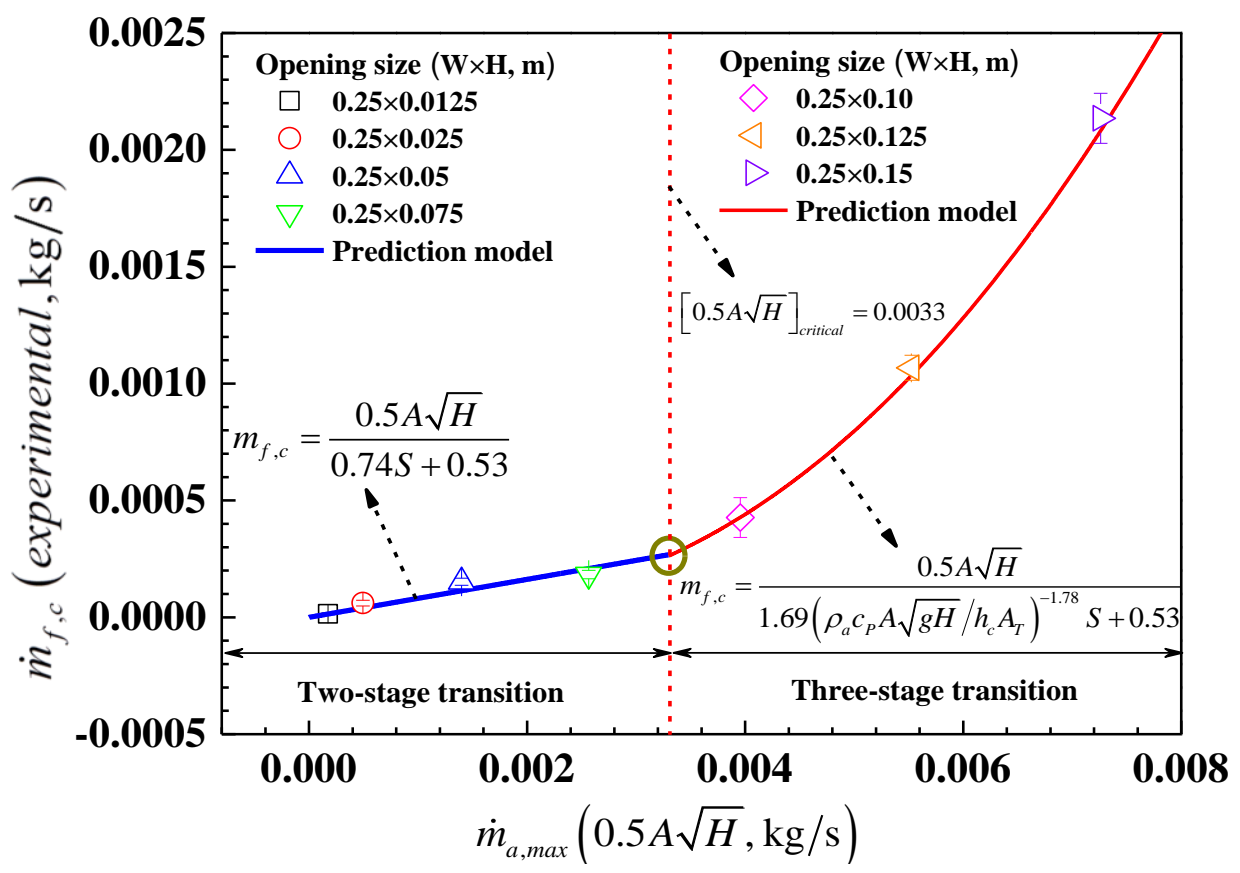

Fig.7 Critical fuel supply mass flow rate as a function of the ventilation factor of the opening for both two-stage transition and three-stage transition, and the approaching by proposed piece-wise function 


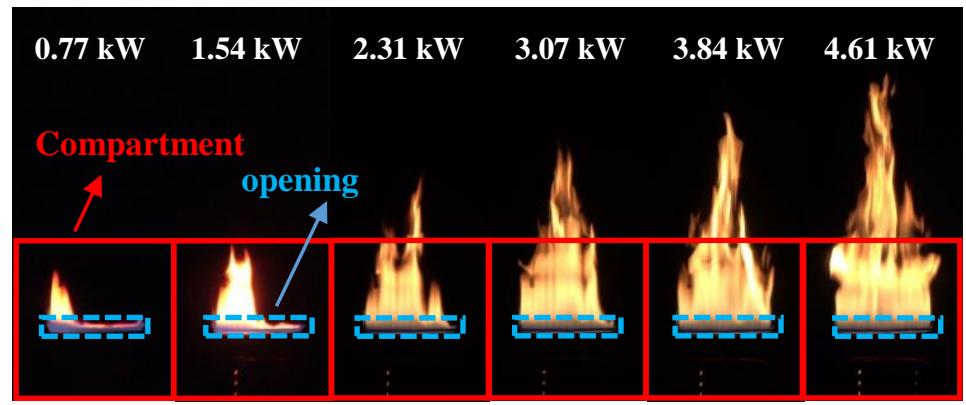

(a): Opening size: $0.25 \mathrm{~m}(W) \times 0.0125 \mathrm{~m}(H)$

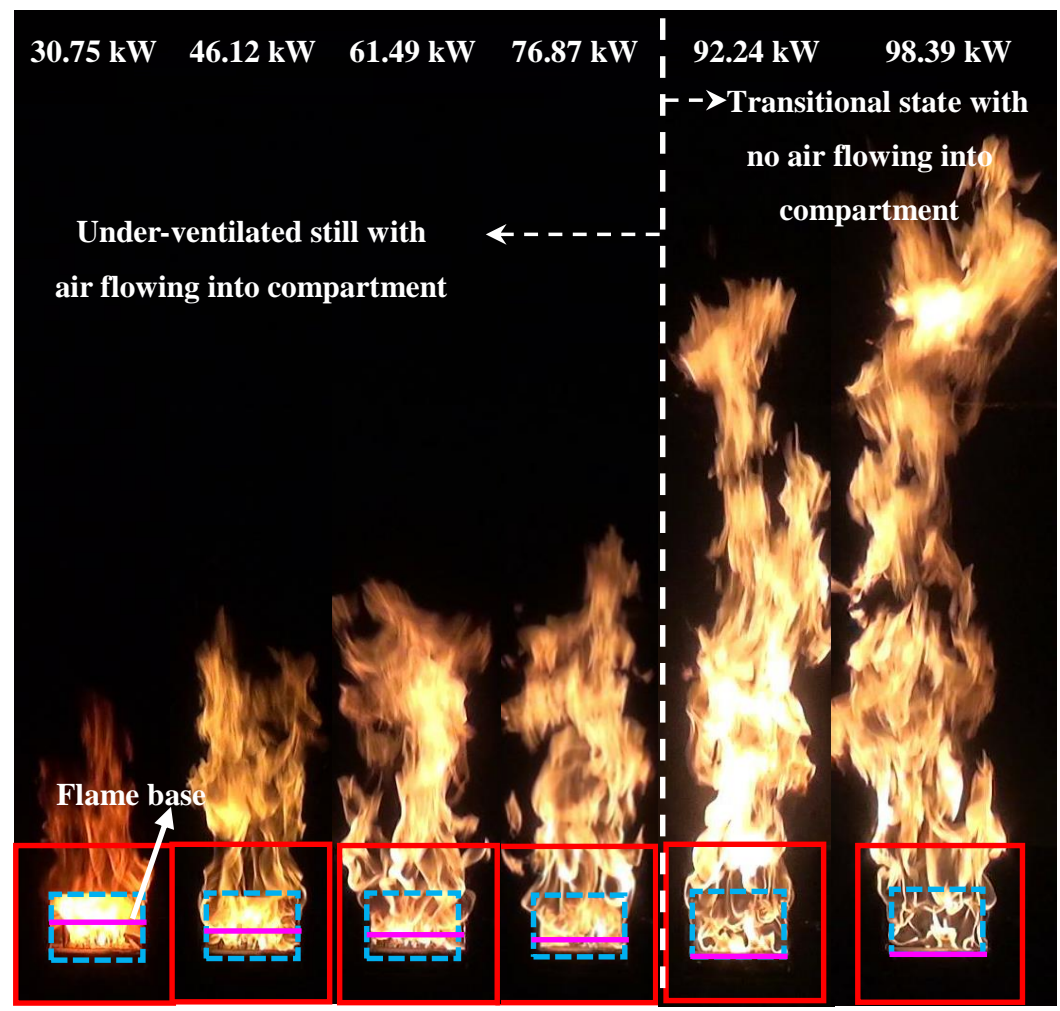

(b): Opening size: $0.25 \mathrm{~m}(W) \times \mathbf{0 . 1 5 m}(H)$

Fig.8 Two types of facade flame height evolution with increasing of fuel supply heat release rate for under-ventilated compartment fire 


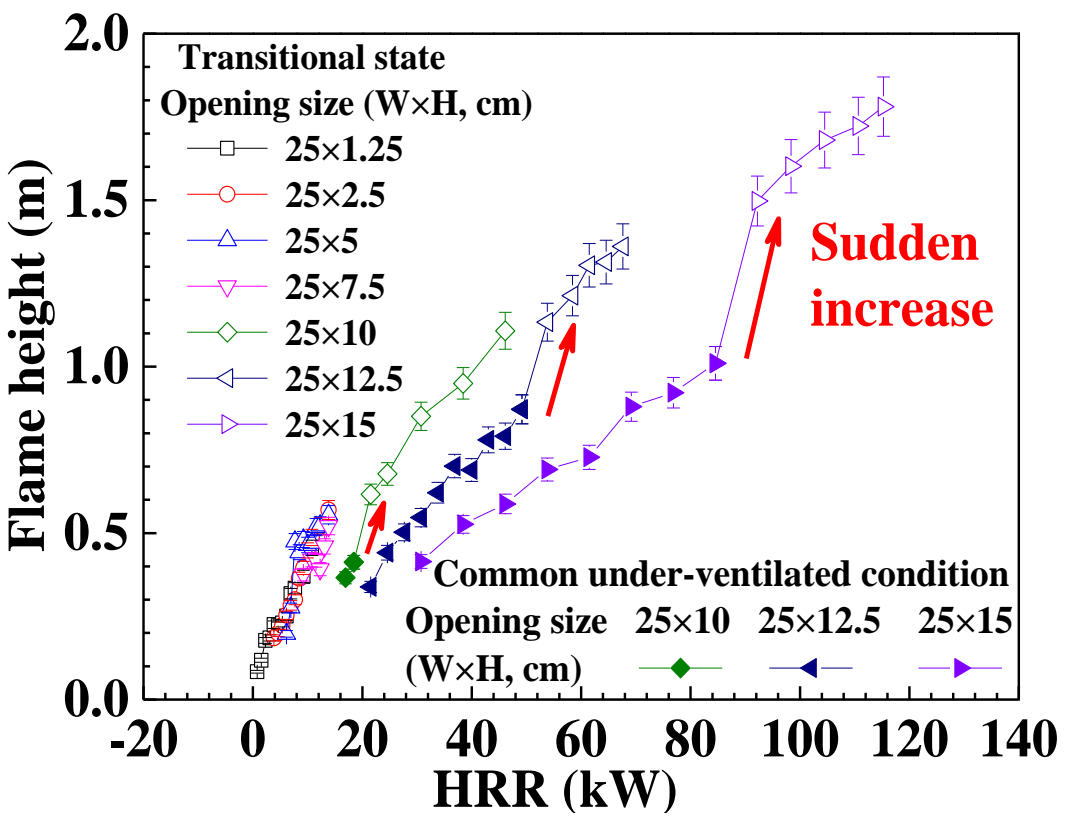

Fig.9 Measured facade flame height with increasing of fuel supply heat release rate showing quantitatively its sudden change when turning to the transitional state 


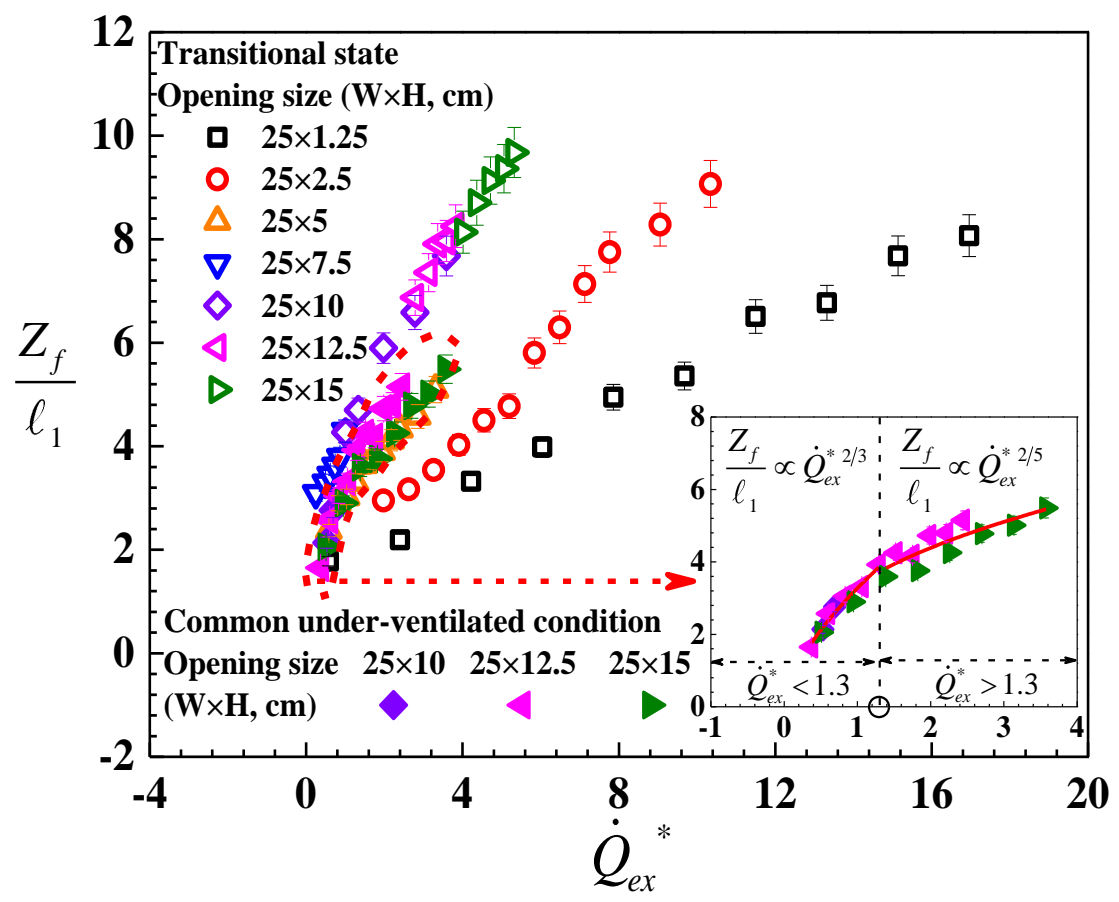

Fig.10 Plot of normalized facade flame height against dimensionless excess heat release rate for various openings based on the classic model (Eq. 1) 
(a)

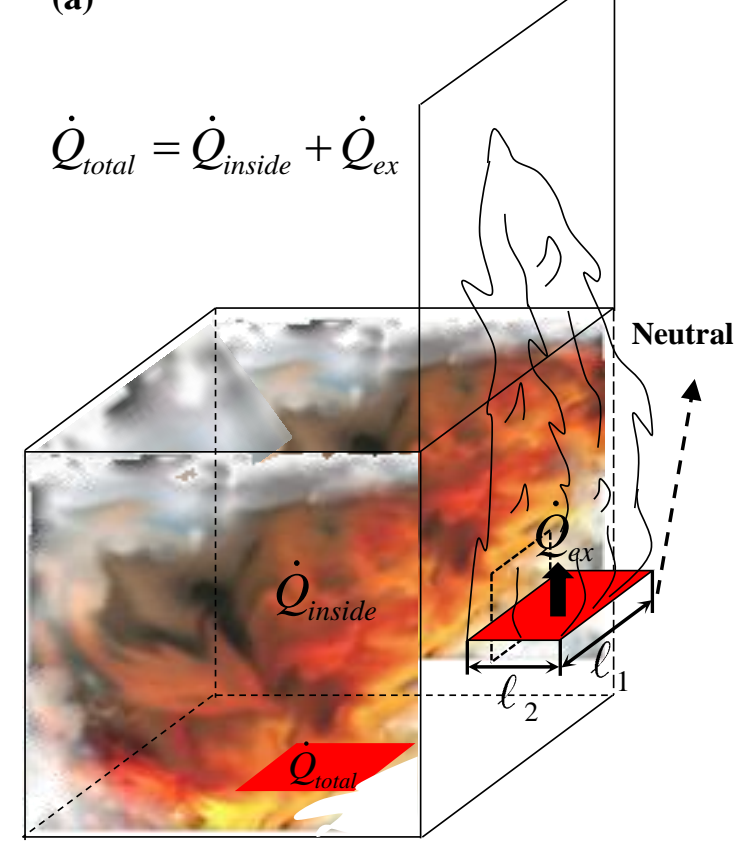

(b)

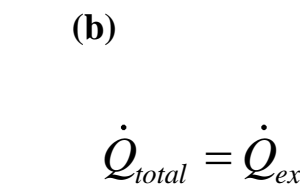

Fig.11 A physical interpretation and modeling of facade flame height for the transitional state

(b) and comparison with the classic model [7] (a) 


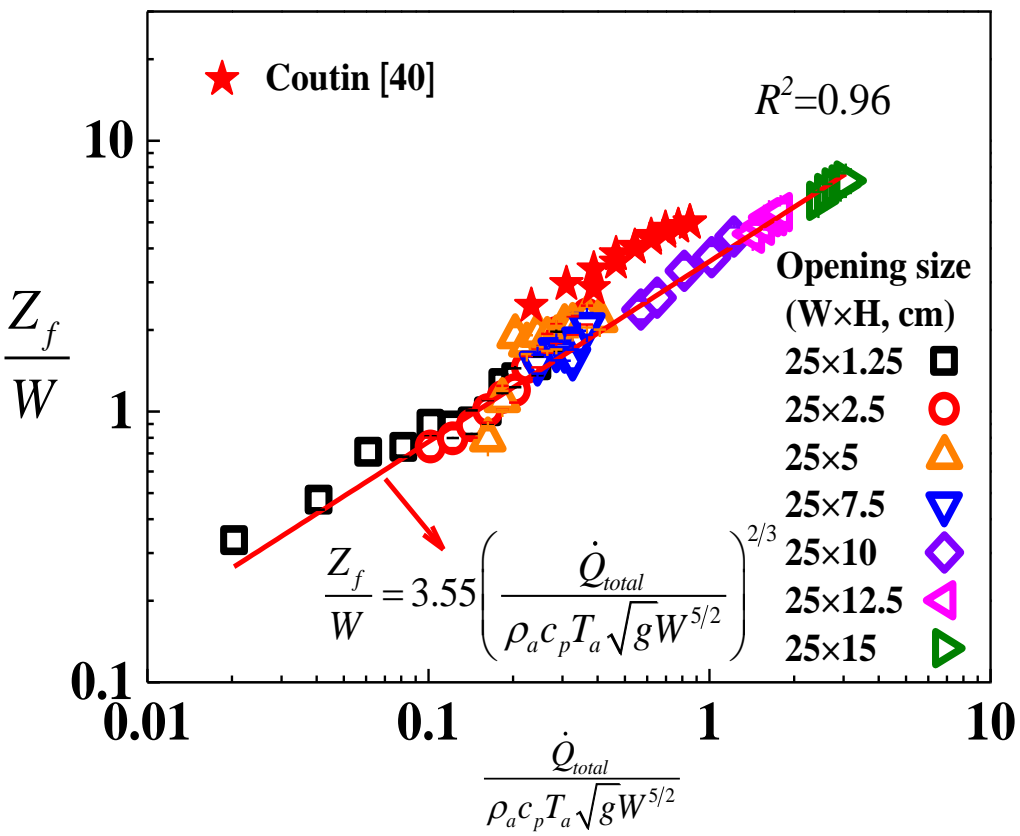

Fig.12 A proposed new correlation of facade flame height with total heat release rate for various openings for the transitional state of under-ventilated condition 
Figure 1: Experimental setup.

Figure 2: Variation of gas temperature inside the compartment with heat release rate and associated flame phenomenon for each opening (Stage I : well-ventilated state; Stage II : under-ventilated state; Stage III: a transitional state of under-ventilated condition).

Figure 3: Variation of air mass inflow with fuel mass flow rate based on the theoretical analysis of mass conservation.

Figure 4: The critical opening size for dividing the two kinds of transitions and the correlation of the critical fuel supply flow rate for relatively small openings reaching the transitional state.

Figure 5: Correlation of the value $\chi$ for critical fuel supply flow rate against the air mass inflow rate for classical under-ventilated fire.

Figure 6: Comparison of experimental values of critical fuel supply mass flow rates with the proposed model for various opening sizes

Figure 7: Critical fuel supply mass flow rate as a function of the ventilation factor of the opening for both two-stage transition and three-stage transition, and the approaching by proposed piece-wise function

Figure 8: Two types of facade flame height evolution with increasing of fuel supply heat release rate for under-ventilated compartment fire.

Figure 9: Measured facade flame height with increasing of fuel supply heat release rate showing quantitatively its sudden change when turning to the transitional state.

Figure 10: Plot of normalized facade flame height against dimensionless excess heat release rate for various openings based on the classic model (Eq. 1). 
Figure 11: A physical interpretation and modeling of facade flame height for the transitional state (b) and comparison with the classic model [7] (a).

Figure 12: A proposed new correlation of facade flame height with total heat release rate for various openings for the transitional state of under-ventilated condition. 